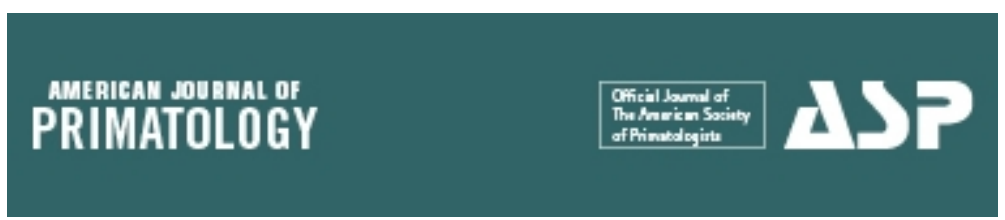

\title{
Density and distribution of western chimpanzees around a bauxite deposit in the Boé Sector, Guinea-Bissau.
}

\begin{tabular}{|c|c|}
\hline Journal: & American Journal of Primatology \\
\hline Manuscript ID & AJP-18-0127.R4 \\
\hline Wiley - Manuscript type: & Research Article \\
\hline $\begin{array}{r}\text { Date Submitted by the } \\
\text { Author: }\end{array}$ & $n / a$ \\
\hline Complete List of Authors: & $\begin{array}{l}\text { Dias, Filipe; Universidade de Lisboa, Instituto Superior de Agronomia; } \\
\text { Universidade do Porto, Centro de Investigação em Biodiversidade e } \\
\text { Recursos Genéticos; Universidade de Lisboa, School of Agriculture } \\
\text { Wenceslau, José; Foundation Chimbo, } \\
\text { Miller, David; University of Saint Andrews, Centre for Research into } \\
\text { Ecological \& Environmental Modelling and School of Mathematics and } \\
\text { Statistics } \\
\text { Marques, Tiago; University of Saint Andrews, Centre for Research into } \\
\text { Ecological \& Environmental Modelling and School of Mathematics and } \\
\text { Statistics; Universidade de Lisboa Departamento de Estatistica e } \\
\text { Investigacao Operacional, Departamento de Estatística e Investigação } \\
\text { Operacional }\end{array}$ \\
\hline $\begin{array}{r}\text { Indicate which taxonomic } \\
\text { group was the subject of your } \\
\text { study (select all that apply or } \\
\text { type another option): }\end{array}$ & Apes (non-human), Pan troglodytes verus \\
\hline Keywords: & $\begin{array}{l}\text { western chimpanzee, Boé, bauxite mining, Guinea-Bissau, Density } \\
\text { surface modelling }\end{array}$ \\
\hline
\end{tabular}

\section{SCHOLARONE" \\ Manuscripts}


1 Title: Density and distribution of western chimpanzees around a bauxite deposit in

2 the Boé Sector, Guinea-Bissau.

3

4 Running title: Western chimpanzees of Boé Sector.

5

6 José F. C. Wenceslau ${ }^{1}$ and Filipe S. Dias ${ }^{2,3,4^{*}}$, Tiago A. Marques ${ }^{5,6}$ and David L.

7 Miller $^{6}$

8

9 José F. C. Wenceslau and Filipe S. Dias should be considered joint first authors

10

$11{ }^{1}$ Foundation Chimbo, Amsterdam, The Netherlands

$122^{2}$ Centre for Applied Ecology "Prof. Baeta Neves" (CEABN - InBIO), School of

13 Agriculture, University of Lisbon, Tapada da Ajuda, 1349-017 Lisbon, Portugal

$14{ }^{3} \mathrm{CIBIO} / \mathrm{InBio}$, Centro de Investigação em Biodiversidade e Recursos Genéticos,

15 Laboratório Associado, Universidade do Porto, Campus Agrário de Vairão, 4485-

16661 Vairão, Portugal

$17{ }^{4} \mathrm{ClBIO} / \mathrm{InBio}$, Centro de Investigação em Biodiversidade e Recursos Genéticos,

18 Laboratório Associado, Instituto Superior de Agronomia, Universidade de Lisboa,

19 Tapada da Ajuda, 1349-017 Lisbon, Portugal

$20{ }^{5}$ Centre for Research into Ecological \& Environmental Modelling and School of

21 Mathematics \& Statistics, University of St Andrews, St Andrews, Scotland, United

22 Kingdom 
$23{ }^{6}$ Centro de Estatística e Aplicações da Universidade de Lisboa, Departamento de

24 Biologia Animal, Faculdade de Ciências da Universidade de Lisboa, Portugal 25

$26{ }^{*}$ Correspondence to: Filipe Dias (fsdias@isa.ulisboa.pt), CIBIO - Instituto Superior

27 de Agronomia Tapada da Ajuda), Tapada da Ajuda, 1349-017 Lisboa 


\section{$28 \quad$ Research Highlights}

29

30 - Approximately 18 nest building western chimpanzees inhabit the

31 surroundings of a bauxite deposit in the SW of Guinea-Bissau;

32

33 - The construction of a mine can have adverse direct and indirect effects on

34 this population.

35

36

37

38

39

40

41

42

43

44

45

46

47

48

49 


\section{Abstract}

51 The Boé sector in southeast Guinea-Bissau harbors a population of western

52 chimpanzees (Pan troglodytes verus) that inhabits a mosaic of forest and savanna.

53 The Boé sector contains a substantial bauxite deposit in a region called Ronde Hill,

54 and there are plans for the construction of a mine, which may endanger the

55 chimpanzee population. In a one-week survey in May 2013, we used the standing

56 crop nest counts method to obtain the number of chimpanzee nests and from that

57 estimate the density and abundance of chimpanzees. We carried out five $1 \mathrm{~km}$ line

58 transects that covered the bauxite deposit and surrounding valleys. We used

59 density surface modeling to analyze habitat preferences, then predicted

60 chimpanzee nest density and distribution based on environmental variables. We

61 found the projected location of the mine partially coincides with an area of high

62 predicted abundances of chimpanzee nests and is surrounded by highly suitable

63 areas for chimpanzees (northeast and southwest). We conclude the mine could

64 have significant direct and indirect effects on this population of chimpanzees

65 whose impacts must be carefully considered and properly mitigated if the mine is 66 built.

67

68 Keywords: western chimpanzee, Boé, bauxite mining, Guinea-Bissau, Density

69 Surface Modelling

70 


\section{Introduction}

Western chimpanzees (Pan troglodytes verus, Schwarz) are a subspecies of chimpanzee whose distribution ranges from tropical lowland forests in Liberia, Côte

74 d'Ivoire, and Sierra Leone to savannas in Guinea, Guinea-Bissau, Senegal, and

75 Mali, that can also inhabit some highly humanized agro-forestry systems in these 76 regions (Kühl et al., 2017). Western chimpanzees are currently listed as Critically

77 Endangered in the International Union for the Conservation of Nature's Red List

78 (Humle et al., 2016). The population of western chimpanzees declined by $80 \%$ and

79 lost $20 \%$ of its range from 1990 to 2014 (Kühl et al., 2017). The most significant

80 losses occurred in Côte d'Ivoire, where the population declined by $90 \%$, mostly due

81 to deforestation, poaching, and infectious diseases (Campbell, Kuehl, N'Goran

82 Kouamé \& Boesch, 2008). In Senegal and Ghana, there are fewer than 1000

83 individuals (Kormos \& Bakarr 2003; Danquah, Oppong, Akom \& Sam, 2012) and in

84 Benin, Togo and Burkina-Faso western chimpanzees are probably extinct (Ginn,

85 Robison, Redmond \& Nekaris, 2013; Khül et al., 2017).

86 In Guinea-Bissau, chimpanzees were declared extinct in 1988, but subsequent

87 surveys found populations in the Quinara and Tombali regions (in the southwest)

88 and in Medina do Boé (a sector south of the Gabu region; Gippoliti, Embalo \&

89 Sousa, 2003; Brugiere, Badjinca, Silva \& Serra, 2009). No country-wide

90 abundance estimates are available for Guinea-Bissau, but some surveys suggest

91 the population may range between 600 and 1000 individuals (Gippoliti et al. 2003).

92 A study in Lagoas de Cufada Natural Park, in Quinara region, estimated 137

93 individuals (95\% Cl: 51-390) (Carvalho, Marques \& Vicente, 2013). In Southern 
94 Cantanhez National Park, in the Tombali region, a study reported fewer than 100

95 chimpanzees (Sousa, Barata, Sousa, Casanova, \& Vicente, 2011). In the Boé

96 sector, Serra, Silva, \& Lopes (2007) interviewed hunters and other knowledgeable

97 locals and came to an estimate of 710 individuals. The main threat to western

98 chimpanzees in Guinea-Bissau is habitat loss and fragmentation due to expanding

99 plantations of banana, cashew, and other fruits (Gippoliti et al., 2003). Expansion

100 of mining operations can also impact chimpanzees, as some studies conducted in

101 other West African countries have suggested (Diallo, 2010; Humle et al., 2016).

102 Mining operations can have direct and indirect impacts on great apes (Arcus

103 Foundation, 2014). The construction of mines can cause habitat loss, and mining

104 operations can cause water contamination and habitat degradation (Kusin et al.,

105 2017, Mensah et al., 2015). The noise from mineral extraction can disturb apes

106 and cause them to move to other areas, thus disrupting their behaviors and social

107 structure. The construction of roads for transporting minerals and workers can

108 cause habitat loss, fragmentation, and increase disturbance (Arcus Foundation,

109 2014, Carvalho et al., 2013, Gippoliti et al., 2003; Hockings \& Humle, 2009). The

110 influx of new workers brought to work on mines can increase bushmeat hunting

111 (Laurence et al., 2005) and promote conversion of forest into agricultural areas to

112 cultivate crops. Frequent contact between humans and chimpanzees can also

113 increase the probability of transmission of diseases for which chimpanzees lack

114 immunity, such as bacterial respiratory diseases (Köndgen et al., 2008) and Ebola

115 (Arcus Foundation, 2014, Devos, Sanz, Morgan, Onononga \& Laporte, 2008).

116 
117 The Boé sector is located in the southeast of Guinea-Bissau and presents the

118 highest altitudes in the country. The region contains lateritic plateaus, mostly close

119 to the border with Guinea, with considerable amounts of bauxite (Diallo, 2010).

120 Ronde Hill is where bauxite prospecting first began in the 1970 s by Russian

121 investors. In 2008, Bauxite Angola S.A. continued prospecting in association with

122 Compagnie Bauxite de Guinée and built a road in the region. This road connects

123 the deposit with the Republic of Guinea and is meant to facilitate the transportation

124 of machinery for bauxite exploitation (Wit, 2011). Mining has not started and is

125 contingent on agreements between Bauxite Angola S.A. and the Guinea-Bissau

126 government that include the improvement of transportation infrastructure. Mining

127 would take place at the crest of the hill, an area important for maintaining water

128 quantity and quality in the Jabere and Paramaka rivers and adjacent valleys (Wit,

129 2011). Since these valleys host a population of western chimpanzees (Wit, 2011),

130 it is crucial to assess the distribution of chimpanzees to understand the possible

131 effects of mining and to develop mitigation strategies.

132 Here we estimate the abundance and distribution of chimpanzee populations in

133 Ronde Hill and adjacent valleys to assess the potential impacts of a bauxite mine.

134 We 1) determined the density and abundance of nest building chimpanzees based

135 on the distribution of nests and 2) analyzed the overlap between chimpanzee nests

136 and the mining area to assess potential impacts.

137

138

139 


\section{Methods}

\section{Study area}

142 The survey was conducted over approximately $47 \mathrm{~km}^{2}$, comprising Ronde Hill, 143 which includes the prospected bauxite deposit, and the basins of the rivers

144 Paramaka and Jabere rivers and its tributaries, Barquere, Gra, Jabeje, Mussa and

145 Tuncotanca creeks (Fig. 1). This site is in the southern limit of the Boé sector,

146 which is close to the border with the Republic of Guinea $\left(11^{\circ} 41^{\prime} \mathrm{N}, 13^{\circ} 54^{\prime} \mathrm{W}\right)$. The

147 nearest human settlements are the villages of Capebonde in Guinea-Bissau and

148 Paramakadow and Paramakaley on the Guinean side of the border. Soils in Ronde

149 Hill are shallow and mostly in the early stages of laterization. As a consequence,

150 savanna is predominant, and forests occur only where the topsoil layer is deeper

151 than one meter and does not flood for prolonged periods (Wit \& Reintjes, 1989).

\section{Ethics statement}

153 The present study complies with the Principles for the Ethical Treatment of

154 Non-Human Primates of the American Society of Primatologists. This research was

155 also approved by Guinea-Bissau's Instituto da Biodiversidade e das Areas

156 Protegidas (IBAP). Since the sampling methods we used did not require direct

157 contact between researchers and chimpanzees, disturbance and health threats to

158 chimpanzees were minimal.

160

161

162 


\section{Estimating the abundance of chimpanzees}

164 Since directly counting chimpanzees is often impractical, surveyors usually use

165 indirect methods. In our case this involved counting nests, which chimpanzees

166 build using branches and leaves. Nests are relatively easy to detect, remain visible

167 for weeks, months, or even years and can be counted with distance sampling

168 techniques (Buckland et al. 2001, Thomas et al. 2010). Chimpanzee abundances

169 can then be estimated by combining the density of nests with nest construction

170 rates, nest decay rates, and the proportion of the population that builds the nests 171 (see below).

172 We established five parallel transects (each $1 \mathrm{~km}$, North-South orientation) that

173 were spaced one kilometer apart and encompassed Ronde Hill and adjacent

174 valleys. During the first week of May 2013, three people followed the Standing

175 Crop Nest Count (SCNC) protocol (Spehar et al., 2010): they walked along each

176 transect carrying a GPS device (Garmin eTrex 10) and recorded the coordinates of

177 chimpanzee nests and the perpendicular distance between each nest and the

178 transect with a measuring tape. The decay stage of each nest was recorded

179 following the scale used by Plumptre \& Reynolds (1997): 1- if the nest is still fresh

180 and stable, with green leaves and feces or feeding signs underneath, 2- if it is still

181 solid, but the leaves have signs of drying, 3- if the nest presents only dried leaves

182 and/or is starting to lose its structure, and 4- if it lost every leaf but is still 183 recognizable as a nest due to the presence of broken branches and twigs. The

184 surrounding environment around each nest was also classified according to four 185 categories: 1) "primary forest" for pristine forested habitats or forests in later 
186 successional stages, 2) "secondary forest" for agricultural land abandoned for

187 longer than five years that present dense mid-story and is starting to regain canopy

188 closure, 3) "fallow" for agricultural fields abandoned for less than four years or still

189 active, and 4) "savanna" for open or sparsely arborized grasslands. Contrary to the

190 work of Bryson-Morrison, Tzanopoulos, Matsuzawa \& Humle (2017) in Bossou,

191 Republic of Guinea, our classification of "primary forest" encompasses mature and

192 riverine forests, our "secondary forest" category includes young secondary forests

193 and our "fallow" class corresponds to all types of highly disturbed habitats they

194 identified in their study.

195 Chimpanzees tend to build nests in groups (Ogawa, Idani, Moore, Pintea \&

196 Hernandez-Aguilar, 2007). As recommended by Buckland et al. (2001), we

197 considered clusters of nests as our observation unit instead of individual nests. To

198 create clusters, we grouped nests with the same age class that were within 20

199 meters of each other post hoc. Some studies have used thresholds of 50 meters

200 (e.g., Morgan \& Sanz, 2006; Sousa et al., 2011), but based on our observations in

201 the field we decided to choose 20 meters to reduce the risk of grouping different

202 clusters together (see Marchesi, Marchesi, Fruth \& Boesch 1995, Ogawa et al.

203 2007, Kouakou, Boesch, \& Kuehl 2009).

204 Since chimpanzees show marked preferences for nesting sites (Carvalho,

205 Meyer, Vicente \& Marques, 2015; Bryson-Morrison et al., 2017), we used Density

206 Surface Modelling (DSM) to model the abundance of clusters of nests (Hedley \&

207 Buckland, 2004; Miller, Burt, Rexstad \& Thomas, 2013) as a function of

208 environmental covariates that include topographic variables, distance to rivers, 
209 roads and villages, percentage of cover of different land uses and Shannon-Wiener

210 land-use diversity (Table 1). Each of the transects was split into five 200 meter

211 segments for modelling. This is a two-stage approach that involves 1) fitting a

212 detection function to the clusters of nests and using it to estimate abundances in

213 transect segments with a Horvitz-Thompson-like estimator (Borchers, Buckland,

214 Goedhart, Clarke, \& Hedley, 1998) and 2) building a generalized additive model

215 (Wood, 2017) to model estimated cluster abundances per transect segment as a

216 function of environmental covariates.

217 We fitted uniform, half-normal and hazard-rate detection functions and included

218 observation-level covariates that may have affected nest detection, such as nest

219 cluster size, mean nest age class and land use cover (savanna, primary forest,

220 secondary forest or fallows). In dense forests and areas with dense understory,

221 nest detection can be lower. Observed distances were truncated at 50 meters

222 based on the visual inspection of the detection function superimposed on a

223 histogram of distances (Buckland et al., 2001) (Appendix 1). The goodness of fit of

224 each detection function was assessed with the Cramer-von Mises test and the

225 Kolmogorov-Smirnov test (Buckland et al., 2004). The best detection function was

226 selected using the Akaike's Information Criteria (AIC). All calculations were

227 performed in R 3.6 ( $R$ Core Team, 2019) using the package "Distance" version

$228 \quad 0.9 .8$ (Miller, Rexstad, Thomas, Marshall \& Laake, 2016).

229 We used Generalized Additive Models (GAMs) to model the abundance of

230 clusters of nests. The expected abundance in each segment was modeled with

231 Tweedie or negative binomial distribution as a function of several covariates. 
232 GAMs were fitted with the R package "dsm" version 2.2.17 (Miller et al., 2013).

233 Thin plate regression splines (Wood, 2003) were used as the basis for the model's

234 smooth terms. The model is initiated by considering that the fit is extremely wiggly.

235 Then the fitting procedure induces a penalization that essentially means the final

236 wigglyness is driven by the data. (Wood, 2017). To minimize the effects of

237 correlation among covariates, we considered only those variables with an

238 individually significant association $(p<0.05)$ with nest cluster abundance.

239 Furthermore, we calculated variance inflation factors (VIF; Fox \& Weisberg, 2010)

240 and eliminated covariates with a VIF $>3$. After fitting the model with all variables,

241 we removed non-significant terms to reduce concurvity. Smoothness selection was

242 performed via restricted maximum likelihood (REML). Smooth terms were selected

243 using approximate $p$-values $(p<0.05)$ and by adding an additional penalty that

244 allowed each smooth term to be removed during model fitting (Marra and Wood,

245 2011). Spatial autocorrelation was assessed by examining a correlogram of

246 deviance residuals. To validate the final models, we analyzed deviance residuals

247 and checked for normal distribution and constant variance (Wood, 2017). To

248 calculate the density of chimpanzees we divided the estimated nest density by the

249 nest production rate and nest decay rate (Plumptre, 2003), following a formula

250 modified after Kühl, Maisels, Ancrenaz \& Williamson (2008):

$251 \quad \mathrm{D}_{\text {weanedchimpanzees }}=\frac{\mathrm{D}_{\text {allnests }}}{r \times \mathrm{t}}$

252 Where $r$ is the estimated rate of nest production per individual per day and $t$ is the

253 estimated mean life of a nest. Both values can be calculated only by performing 
254 detailed field studies and may vary between populations and geographic areas.

255 Because of time constraints, we could not estimate these parameters in our study 256 area, so we used estimates from other studies. For $r$ we used 1.09 nests/day per 257 individual from Plumptre \& Reynolds (1997) in Budongo Forest Reserve, Uganda.

258 For $t$ we chose 194 days from Fleury-Brugiere \& Brugiere (2010) in the Haut Niger

259 National Park, Republic of Guinea. This estimate was considered the most suitable 260 given the proximity to our study area and similarities in climate and vegetation.

261 Unfortunately, these studies did not provide the variances for these parameters.

262 Therefore the variances of chimpanzee densities will be underestimated.

263 To assess the potential impacts of the construction of the mine on 264 chimpanzees, we used the density surface model to calculate the predicted 265 abundance of nests in the study area. We combined uncertainty from the spatial 266 model (GAM) with that of detectability (detection function) using the delta method 267 (assuming independence between these two components) using "dsm.var.gam" 268 from the R package "dsm" (Miller et al 2013). Finally, we analyzed the overlap 269 between the bauxite deposit and the areas where the model predicts higher 270 abundances of nests.

271

272 3. Results

273 We counted 608 nests during the surveys, which we grouped in 116 clusters.

274 The number of nests per cluster averaged $5.2 \pm$ SD 6.7.

275

276 


\section{Detection function}

278 We selected a hazard-rate key function with cluster size as a covariate by AIC.

279 The truncation distance for the detection function was $50 \mathrm{~m}$ and selected by 280 comparing test statistics from the Cramer-von Mises and Kolmogorov-Smirnov

281 goodness of fit tests. The average detection probability was 0.534 , and the 282 coefficient of variation was 0.068 (Fig. 2). A complete comparison of the detection 283 functions can be found in the Supplementary Information (Table S1), along with all 284 the $\mathrm{R}$ code required to reproduce our results. Figure 2 shows relatively few 285 detections close to the transect, which was caused by lower detectability of nests 286 in areas with dense forest or dense understorey. This did not have important 287 effects on the fit of the detection function.

288 Density surface models

289 The density surface model with a Tweedie distribution provided the best fit for 290 the data (see quantile-quantile plot, Fig. 3). The abundance of clusters of nests 291 was higher in areas with a northwest exposure, closer to seasonal rivers, in areas 292 with a low cover of savanna and with a high Shannon-Wiener diversity of land uses 293 (Fig. 4).

\section{Estimated abundance of nests and chimpanzees}

295 The model predicted the occurrence of 3878 nests in the study area. The 296 coefficient of variation from the GAM was 0.2481 , and the coefficient of variation of 297 the detection function 0.1271 . The total coefficient of variation for the estimate was 2980.2788 (calculated using the delta method). Following Equation 1, the estimated 299 abundance of nest building chimpanzees in Ronde hill is $N=18$ (95\% Cl: 11-31). 
300 This estimate corresponds to a density of 0.3898 individuals $/ \mathrm{km}^{2}(95 \% \mathrm{Cl}: 0.2280$

$3010.6664)$.

302 The overlap between chimpanzees' nests and the proposed mine

303 Predicted abundances of nests are not very high ( $<20$ nests $)$ at the top of

304 Ronde hill, where the mine is going to be built (there is some overlap in the

305 northwestern part) (Fig. 5). The overlap between areas with a high predicted

306 abundance of nests $\left(>40\right.$ nests $\left./ \mathrm{km}^{2}\right)$ and the future area of the mine is $0.2 \mathrm{~km}^{2}$.

307

308 4. Discussion

309 In this study, we estimated the distribution and abundance of chimpanzees

310 with the standing crop nest counts method and compared it with the future location

311 of a bauxite mine. Overall, the predicted abundances of nests in location of the

312 mine were relatively low, which can probably be explained by the fact that the top

313 of Ronde Hill is covered by savanna and devoid of suitable trees for building nests.

314 Still, the northeastern part of the mine coincides with an area of high observed and

315 predicted nest density ( $>40$ nests $/ \mathrm{km}^{2}$ ), that also contains the only accessible year-

316 round source of water in a 2 kilometer radius. This area is probably an essential

317 refuge for western chimpanzees, which are already suffering from habitat loss due

318 to agricultural pressure from the neighboring village of Capebonde.

319 We estimated the total abundance of nest building chimpanzees in the study

320 areas was $18(95 \% \mathrm{Cl}: 11-31)$, corresponding to 0.3898 individuals $/ \mathrm{km}^{2}(95 \% \mathrm{Cl}$ :

$3210.2280-0.6664)$. Camera traps active during fieldwork placed in the valley of the

322 Jabere river during identified at least 18 weaned chimpanzees (JFCW et al. 
323 unpublished data). Our estimate is within the range of estimates obtained in other

324 studies that also used the standing crop nest counts method. In Senegal, Pruetz et

325 al. (2002) estimated 0.13 individuals $/ \mathrm{km}^{2}$, in the Republic of Guinea Fleury-

326 Brugiere \& Brugiere (2010) estimated 0.87 individuals $/ \mathrm{km}^{2}(95 \% \mathrm{Cl}: 0.73-1.04)$

327 and in Lagoas de Cufada Natural Park in Guinea-Bissau Carvalho et al. (2013)

328 found 0.22 individuals $/ \mathrm{km}^{2}(95 \% \mathrm{Cl}: 0.08-0.62)$.

329 The density surface model suggests that chimpanzees prefer to build nests in

330 areas facing northeast, with higher Shannon-Wiener land use diversity, with low

331 cover by savanna, and close to seasonal rivers. These results are in line with the

332 findings from other studies, which suggest that western chimpanzees can tolerate

333 some human disturbance (Brugiere et al., 2009; Bryson-Morrison et al., 2017) and

334 inhabit mosaics containing savanna, riparian forests, dense forests and more open

335 habitats (Carvalho et al., 2013, 2015). In Lagoas de Cufada Natural Park (Guinea-

336 Bissau), Carvalho et al. (2015) found that chimpanzees prefer to build nests in

337 dense forests, contrary to our findings. Dense forests in Ronde hill are often close

338 to frequently used agricultural areas which are avoided by chimpanzees. This type

339 of avoidance behavior has also been observed in the Republic of Guinea (Bryson-

340 Morrison et al., 2017).

341 Because of logistical constraints, we could conduct only one survey. We

342 suggest that future research in the study area should focus on analyzing how

343 chimpanzees use habitats throughout the year. It would also be useful to determine

344 whether the chimpanzees that occur in Ronde Hill are part of one or several

345 communities, and whether these communities are connected to those in the 
346 Republic of Guinea. This information would allow us to better understand and

347 prevent the possible impacts of the construction of the mine on this population of

348 western chimpanzees.

349

350

\section{Conclusion}

351 The results of the study show that only a small part of the proposed mine

352 coincides with areas of high chimpanzee's nests abundance. This small area of

353 overlap presents one of the highest abundances of nests in the whole study area

$354\left(>40\right.$ nests $\left./ \mathrm{km}^{2}\right)$. In the remaining area around the mine, predicted nest densities

355 are low, which probably reflects the fact that it is currently covered by grassland

356 savanna and does not contain trees suitable for building nests. The projected

357 location of the mine borders two areas of high abundance of chimpanzee's nests

358 (northeast and southwest), therefore it is likely to be used by chimpanzees. The

359 data we gathered, combined with the existing knowledge on impacts of mining on

360 great ape populations, suggests the construction of the mine is likely to have

361 significant direct and indirect effects on this population of chimpanzees. We

362 recommend that if the mine is approved, authorities should carefully consider direct

363 and indirect impacts on this population of chimpanzees and implement appropriate

364 mitigation and compensation measures.

365

366

367

368 


\section{Acknowledgments}

370 We thank CHIMBO Foundation, especially the director Annemarie

371 Goedmakers and the board advisor Piet Wit for providing logistical and financial

372 support for this survey and for their suggestions that significantly improved this

373 work. We further thank the five CHIMBO's village committee members of

374 Capebonde (Amadou Camará, Mangabói Culubali, Mari Cante, Boibalo Bangura,

375 and Ali Camará) for their help in data collection and colleagues Jitske Willemsen

376 and Menno de Boer for their company and support during the field survey. We are

377 also extremely thankful to Bauxite Angola S.A. for providing us with their

378 prospecting data and for the meeting with JFCW to discuss possible outcomes of

379 this research. This work was approved by the Instituto da Biodiversidade e das

380 Áreas Protegidas (IBAP) of Guinea-Bissau and complied with the Principles for the

381 Ethical Treatment of Non-Human Primates of the American Society of

382 Primatologists (ASP). JFCW was supported by Ciências sem Fronteiras

383 scholarship from Conselho Nacional de Desenvolvimento Científico e Tecnológico

384 (CNPq), Brazil (grant number 221350/2012-8). FSD was funded by FEDER funds

385 through the Operational Programme for Competitiveness Factors - COMPETE and

386 by National Funds through FCT - Foundation for Science and Technology under

387 the UID/BIA/50027/2013 and POCI-01-0145-FEDER-006821. TAM thanks partial

388 support by CEAUL (funded by FCT - Fundação para a Ciência e a Tecnologia,

389 Portugal, through the project UID/MAT/00006/2019). We also wish to thank the

390 editor and the anonymous reviewers for their comments that significantly improved

391 this manuscript. 
392

393

394

395

396

397

398

399

400

401

402

403

404

405

406

407

408

409

410

411

412

413

\section{References}

Arcus Foundation. (2014). Extractive industries and ape conservation (state of the Apes). https://doi.org/10.1017/CBO9781107590274

Borchers, D. L., Buckland, S. T., Goedhart, P. W., Clarke, E. D., \& Hedley, S. L. (1998). Horvitz-Thompson estimators for double-platform line transect surveys. Biometrics, 54(4), 1221-1237.

Brugiere, D., Badjinca, I., Silva, C., \& Serra, A. (2009). Distribution of chimpanzees and interactions with humans in Guinea-Bissau and Western Guinea, West Africa. Folia Primatologica, 80, 353-358.

https://doi.org/10.1159/000259335

Bryson-Morrison, N., Tzanopoulos, J., Matsuzawa, T., \& Humle, T. (2017). Activity and habitat use of chimpanzees (Pan troglodytes verus) in the anthropogenic landscape of Bossou, Guinea, West Africa. International Journal of Primatology, 38(2), 282-302. http://doi.org/10.1007/s10764-016-

$\underline{9947-4}$

Buckland, S. T., Anderson, D. R., Burnham, K. P., Laake, J. L., Borchers, D. L., \& Thomas, L. (2001). Introduction to Distance Sampling: Estimating Abundance of Biological Populations. New York: Oxford University Press.

Buckland, S. T., Anderson, D. R., Burnham, K. P., Laake, J. L., Borchers, D. L., \& Thomas, L. (2004). Advanced Distance Sampling: Estimating Abundance of Biological Population. New York: Oxford University Press. 
414 Campbell, G., Kuehl, H., N'Goran Kouamé, P., \& Boesch, C. (2008). Alarming decline of West African chimpanzees in Côte d'Ivoire. Current Biology, 18(19), R903-R904. http://doi.org/https://doi.org/10.1016/j.cub.2008.08.015

Carvalho, J. S., Marques, T. A., \& Vicente, L. (2013). Population status of Pan troglodytes verus in Lagoas de Cufada Natural Park, Guinea-Bissau. PloS One, 8(8), e71527. http://doi.org/10.1371/journal.pone.0071527

Carvalho, J. S., Meyer, C. F. J., Vicente, L., \& Marques, T. A. (2015). Where to nest? Ecological determinants of chimpanzee nest abundance and distribution at the habitat and tree species scale. American Journal of 
Guinea-Bissau: AD, Conakry, Guinea: Guinée ecologie, Freetown, Sierra Leone: EFA.

ESRI 2011. ArcGIS Desktop: Release 10. Redlands, CA: Environmental Systems Research Institute.

440 Fleury-Brugiere, M.-C., \& Brugiere, D. (2010). High population density of Pan troglodytes verus in the Haut Niger National Park, Republic of Guinea: Implications for local and regional conservation. International Journal of Primatology, 31(3), 383-392. http://doi.org/10.1007/s10764-010-9391-9

444 Fox, J., \& Weisberg, H. S. (2010). An R companion to applied regression (2nd ed.). Thousand Oaks, CA: SAGE Publications.

446 Ginn, L., Robison, J., Redmond, I., \& Nekaris, K. (2013). Strong evidence that the West African chimpanzee is extirpated from Burkina Faso. Oryx, 47(3), 325-326. doi:10.1017/S0030605313000434

449 Gippoliti, S., Embalo, D. S., Sousa, C. (2003). Guinea-Bissau. In: R. Kormos, C. Boesch, M. I. Bakarr, \& T. M. Butynski (Eds.), West african chimpanzees. status survey and conservation action plan (pp. 55-61). Gland, Switzerland

453 Hedley, S. L., \& Buckland, S. T. (2004). Spatial models for line transect sampling. 454 Journal of Agricultural, Biological, and Environmental Statistics, 9(2), 181. http://doi.org/10.1198/1085711043578

456 Hockings, K., \& Humle, T. (2009). Best practice guidelines for the prevention and 457 mitigation of conflict between humans and great apes. Gland, Switzerland: $458 \quad$ IUCN/SSC Primate Specialist Group (PSG). 
459 Humle, T., Boesch, C., Campbell, G., Junker, J., Koops, K., Kuehl, H. \& Sop, T. 460 2016. Pan troglodytes ssp. verus (errata version published in 2016). The $461 \quad$ IUCN Red List of Threatened Species 2016:

462 e.T15935A102327574. http://dx.doi.org/10.2305/IUCN.UK.2016463 2.RLTS.T15935A17989872.en.

464 Köndgen, S., Kühl, H., N'Goran, P. K., Walsh, P. D., Schenk, S., Ernst, N., ... 465 Leendertz, F. H. (2008). Pandemic human viruses cause decline of endangered great apes. Current Biology, 18(4), 260-264. https://doi.org/10.1016/j.cub.2008.01.012

Kormos, R., \& Bakarr, M.I. (2003). Regional Summary. In: R. Kormos, C. Boesch, 469 M. I. Bakarr, \& T. M. Butynski (Eds.), West african chimpanzees. status survey and conservation action plan (pp. 27-29). Gland, Switzerland and Cambridge, UK: IUCN/SSC Primate Specialist Group (PSG).

472 Kouakou, C. Y., Boesch, C., \& Kuehl, H. (2009). Estimating chimpanzee population 473 size with nest counts: validating methods in Taï National Park. American

475 Kühl, H. S., Maisels, F., Ancrenaz, M., \& Williamson, E. A. (2008). Best practice

476 guidelines for surveys and monitoring of great ape populations. Gland, Switzerland: IUCN/SSC Primate Specialist Group (PSG).

Kühl, H. S., Kalan, A. K., Arandjelovic, M., Aubert, F., D’Auvergne, L., Goedmakers, A., ... Boesch, C. (2016). Chimpanzee accumulative stone throwing. Scientific Reports, 6, 22219. http://doi.org/10.1038/srep22219 
481 Kühl, H. S., Sop, T., Williamson, E. A., Mundry, R., Brugière, D., Campbell, G., ... 482 Boesch, C. (2017). The Critically Endangered western chimpanzee 483 484 485 486 declines by $80 \%$. American Journal of Primatology, 79(9). https://doi.org/10.1002/ajp.22681

Kusin, F. M., Rahman, M. S. A., Madzin, Z., Jusop, S., Mohamat-Yusuff, F., Ariffin, M., \& Z, M. S. M. (2017). The occurrence and potential ecological risk assessment of bauxite mine-impacted water and sediments in Kuantan, Pahang,Malaysia. Environmental Science and Pollution Research, 24(2), 1306-1321. http://doi.org/10.1007/s11356-016-7814-7

Laurance, W. F., Croes, B. M., Tchignoumba, L., Lahm, S. A., Alonso, A. Lee, M. E. \& Ondzeano, C. (2006). Impacts of roads and hunting on central African rainforest mammals. Conservation Biology, 20, 1251-1261. https://doi.org/10.1111/j.1523-1739.2006.00420.x

Marchesi, P., Marchesi, N., Fruth, B., \& Boesch, C. (1995). Census and distribution of chimpanzees in Côte d'Ivoire, Primates, 36(4), 591 - 607. https://doi.org/10.1007/BF02382880

Marra, G., \& Wood, S. N. (2011). Practical variable selection for generalized additive models. Computational Statistics \& Data Analysis, 55(7), 23722387. http://doi.org/https://doi.org/10.1016/j.csda.2011.02.004

Mensah, A. K., Mahiri, I. O., Owusu, O., Mireku, O. D., Wireko, I., \& Kissi, E. A. (2015). Environmental impacts of mining: a study of mining communities in Ghana. Applied Ecology and Environmental Sciences, 3(3), 81-94. http://doi.org/10.12691/aees-3-3-3 
504 Miller, D. L., Rexstad, E., Burt, L., Bravington, M. V., \& Hedley, S. (2019). dsm:

$505 \quad$ Density surface modelling of distance sampling data (Version 2.2.17).

$506 \quad$ Retrieved from https://cran.r-project.org/web/packages/dsm/index.html

507 Miller, D. L., Burt, M. L., Rexstad, E. A., \& Thomas, L. (2013). Spatial models for

508 distance sampling data: recent developments and future directions.

$509 \quad$ Methods in Ecology and Evolution, 4, 1001-1010.

$510 \quad$ https://doi.org/10.1111/2041-210X.12105

511 Miller, D. L., Rexstad, E., Thomas, L., Marshall, L., \& Laake, J. L. (2016). Distance

512 sampling in R. Journal of Statistical Software.

$513 \quad$ http://dx.doi.org/10.1101/063891.

514 Morgan, D., \& Sanz, C. (2007). Best practice guidelines for reducing the impact of

515 commercial logging on great apes in Western Equatorial Africa. Occasional

516 paper of the IUCN Species Survival Commission, No 34, IUCN

517 Ogawa, H., Idani, G., Moore, J., Pintea, L., \& Hernandez-Aguilar, A. (2007).

$518 \quad$ Sleeping parties and nest distribution of chimpanzees in the savanna

519 woodland, Ugalla, Tanzania. International Journal of Primatology, 28(6),

$520 \quad$ 1397-1412. http://doi.org/10.1007/s10764-007-9210-0

521 Plumptre, A. J. (2003). Censuing chimpanzees. In: A. J. Plumptre, D. Cox, \& S.

522 Mugume, (Eds.), The status of chimpanzees in Uganda. Albertine Rift

523 Technical Report Series No. 2. Wildlife Conservation Society, New York.

524 R Core Team (2017). R: a language and environment for statistical computing.

525 Vienna, Austria: R Foundation for Statistical Computing. 
526 Serra, A., Silva, C., \& Lopes, E. (2007). Étude de faisabilité du projet 527 "Développement touristique de la Boé au profit de la conservation des Chimpanzés et des populations locales". Bissau, Guinea-Bissau: WWF, Chimbo Foundation, IUCN and IBAP.

530 Sousa, J., Barata, A. V, Sousa, C., Casanova, C. C. N., \& Vicente, L. (2011).

531 Chimpanzee oil-palm use in southern Cantanhez National Park, Guinea-

532 Bissau. American Journal of Primatology, 73(5), 485-97.

533 http://doi.org/10.1002/ajp.20926

534 Spehar, S. N., Mathewson, P. D., Wich, S. A., Marshall, A. J., Kühl, H., \& Meijaard, 535 E. (2010). Estimating orangutan densities using the standing srop and marked nest count methods: lessons learned for conservation. Biotropica,

540 Wit, P., \& Reintjes, H. C. (1989). An agro-ecological survey of the Boé province,

541 Guinea Bissau. Agriculture, Ecosystems \& Environment, 27(1), 609-620. http://doi.org/https://doi.org/10.1016/0167-8809(89)90121-7

543 Wood, S. N. (2003). Thin plate regression splines. Journal of the Royal Statistical 544 Society: Series B, 65(1), 95-114. https://doi.org/10.1111/1467-9868.00374

545 Wood, S. N. (2017). Generalized Additive Models: An Introduction with R (2nd ed.).

546 Boca Raton, FL: Chapman and Hall/CRC. 
551 Figure 1 - Map showing the study area including the location of Ronde hill, the

552 future location of the mine, transects, nest clusters, roads, rivers and closest

553 villages. The top inset shows the location of Guinea-Bissau and the bottom inset

554 the location of the study area in this country. 


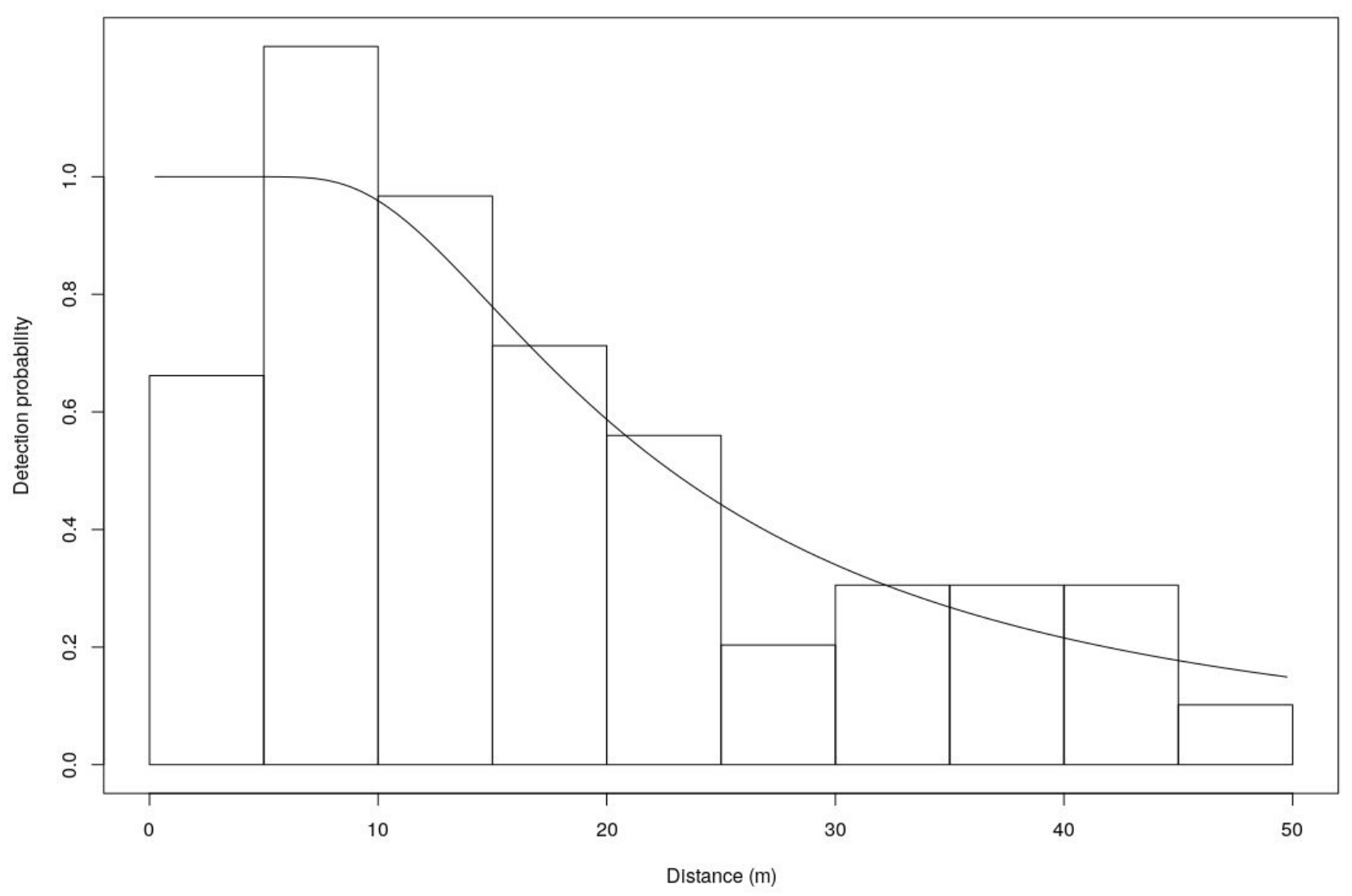

559 Figure 2 - Selected detection function (hazard-rate with cluster size as covariate)

560 for clusters of nests overlaid onto a histogram of observed distances.

561

562

563

564

565

566

567 

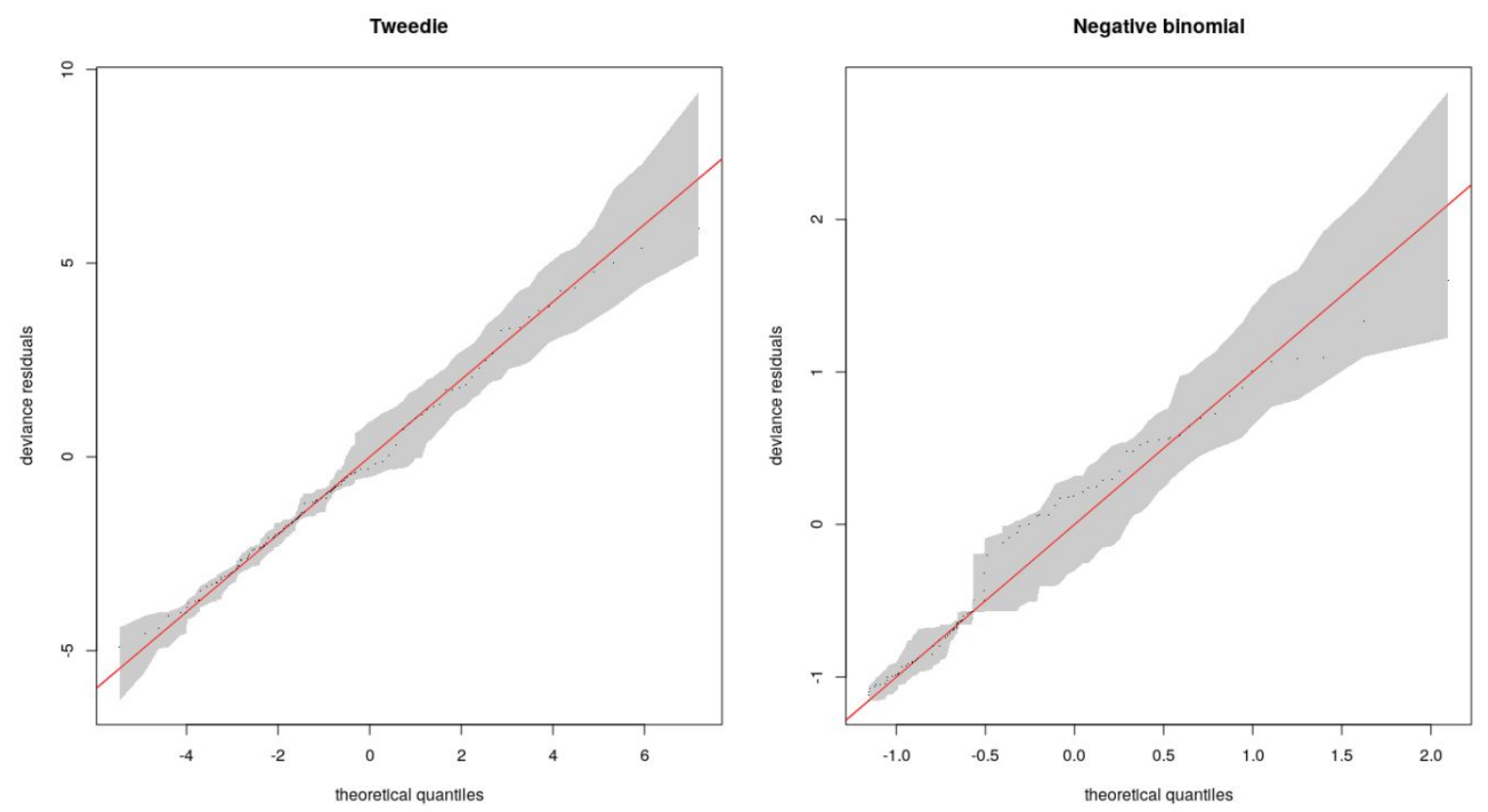

568

569 Figure 3 - Comparison of models with Tweedie (left) and negative binomial (right)

570 response distributions by quantile-quantile plots. Good fit is indicated by agreement

571 between observed and fitted (residual) quantiles (i.e., points being close to the red

572 line). $90 \%$ reference bands are shown in grey allowing judgment of the deviation

573 from the line. The negative binomial points fall further away from the red line than

574 those for the Tweedie, indicating model misspecification.

575

576

577

578

579 

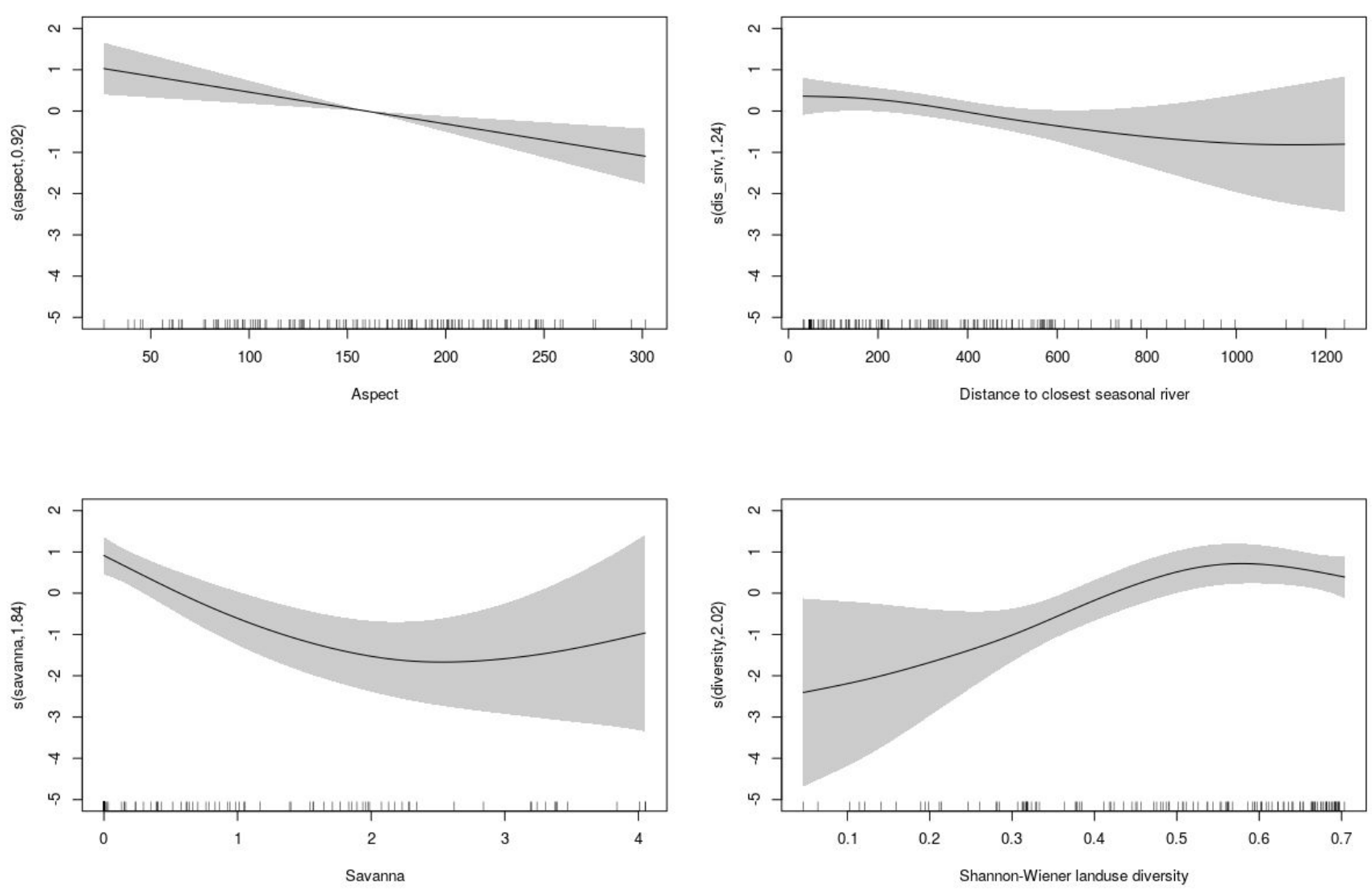

580

581 Figure 4 - Smooth functions for "aspect", "distance to closest seasonal river",

582 "savanna and "Shannon-Wiener" land use diversity. Grey shading corresponds to

$58395 \%$ confidence bands, numbers in brackets on the vertical axis labels give the

584 effective degrees of freedom of the term (1 corresponds to a linear term).

585

586

587 


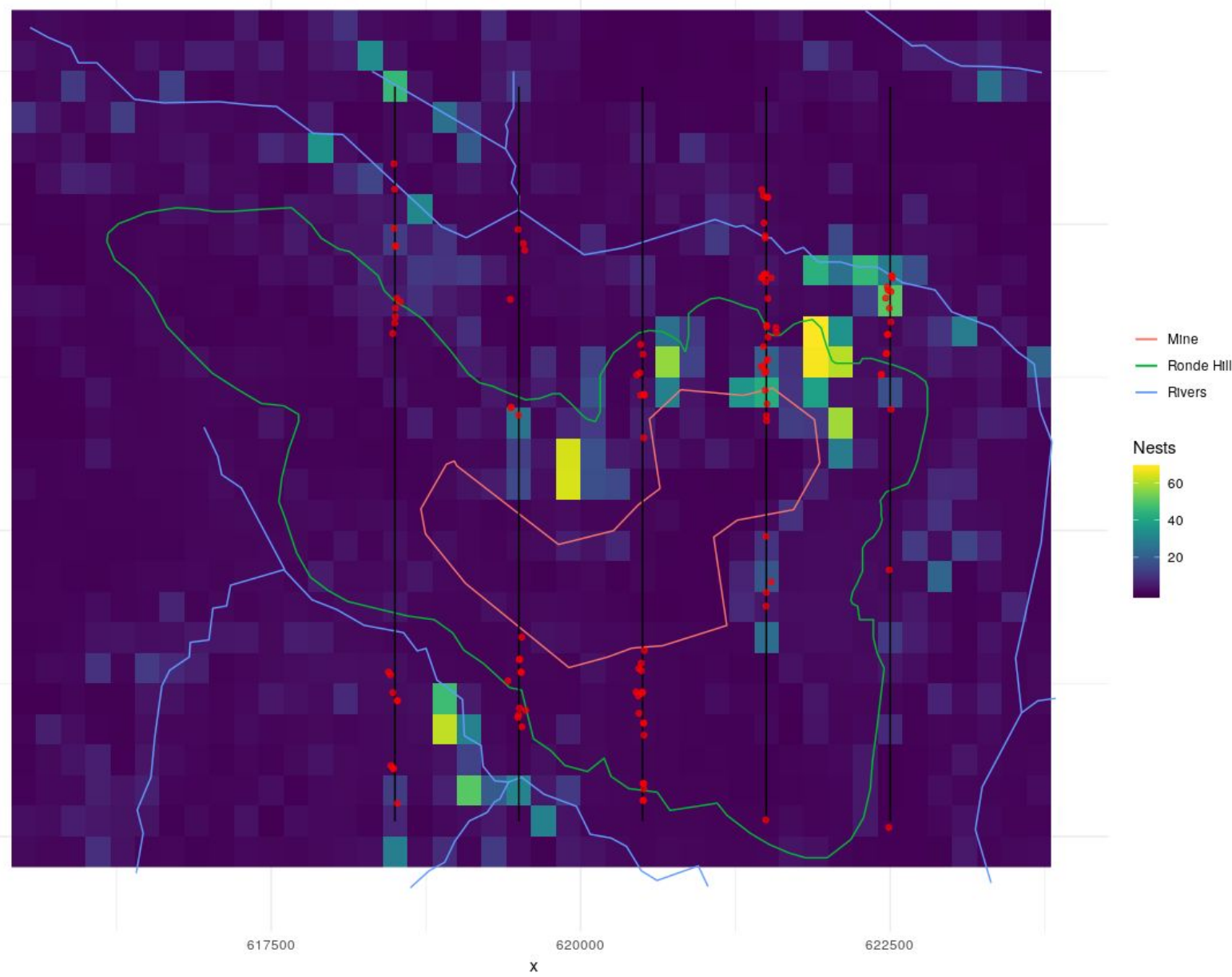

588

589 Figure 5 - Predicted abundance of nests overlaid with the location of the transects

590 (black lines), location of clusters of nests (red dots) and future location of the mine

591 (pink line). Ronde hill is shown by the green line and rivers are shown by blue

592 lines.

593

594

595

596 
597 Table 1 - Covariates used in the spatial model (GAM).

\begin{tabular}{lll}
\hline Variables & Description and Units & Source \\
\hline Slope & Mean slope (degrees) & ASTER GDEM 2.0 \\
Aspect & Mean aspect (radians) & ASTER GDEM 2.0 \\
Altitude & Mean altitude (m) & ASTER GDEM 2.0 \\
Distance to closest permanent river & Distance $(\mathrm{m})$ & JFCW \\
Distance to closest seasonal river & Distance (m) & JFCW \\
Distance to closest village & Distance to the centroid of & JFCW \\
& the closest village (m) & \\
Distance to closest road & Distance (m) & JFCW \\
Agriculture & Area (ha) & JFCW \\
Urban & Area (ha) & JFCW \\
Primary Forest & Area (ha) & JFCW \\
Secondary Forest & Area (ha) & JFCW \\
Savanna & Area (ha) & JFCW \\
Land use diversity & Shannon-Wiener diversity & - \\
& Index & \\
\hline
\end{tabular}




\section{Research Highlights}

- Approximately 18 nest building western chimpanzees inhabit the surroundings of a bauxite deposit in the SW of Guinea-Bissau;

- The construction of a mine can have adverse direct and indirect effects on this population. 


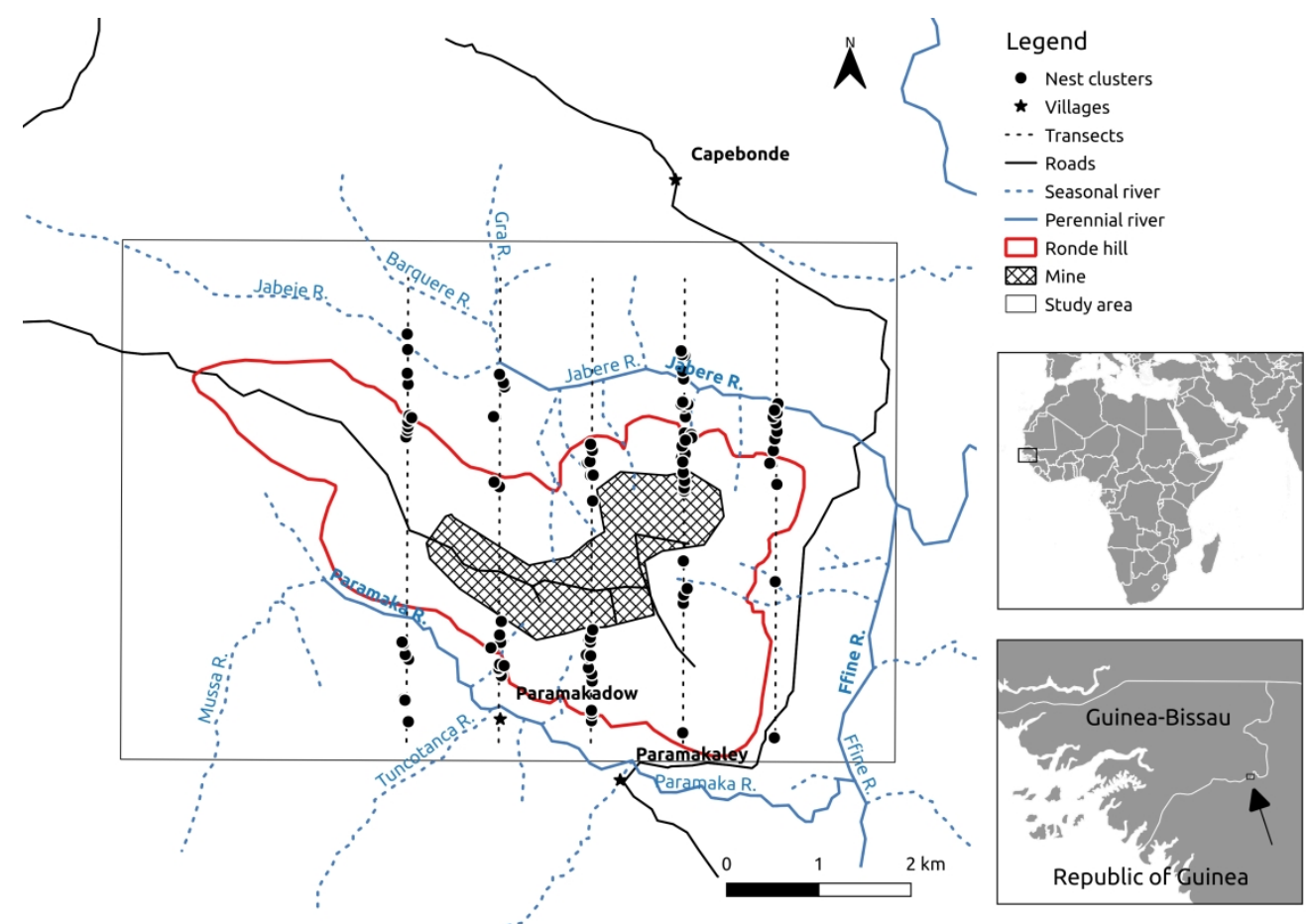

Figure 1

$296 \times 209 \mathrm{~mm}(300 \times 300 \mathrm{DPI})$ 


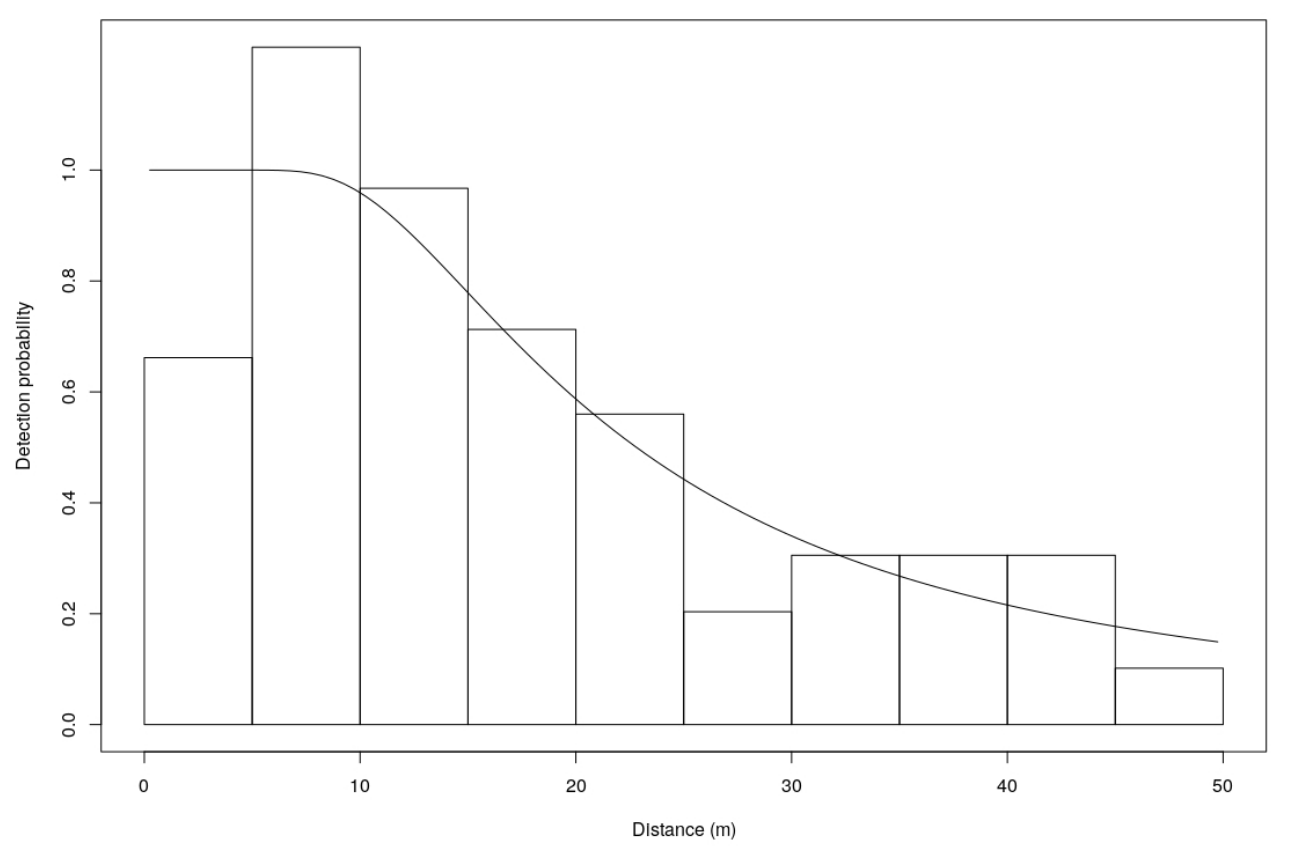

Figure 2

$396 \times 285 \mathrm{~mm}(72 \times 72$ DPI $)$

John Wiley \& Sons 

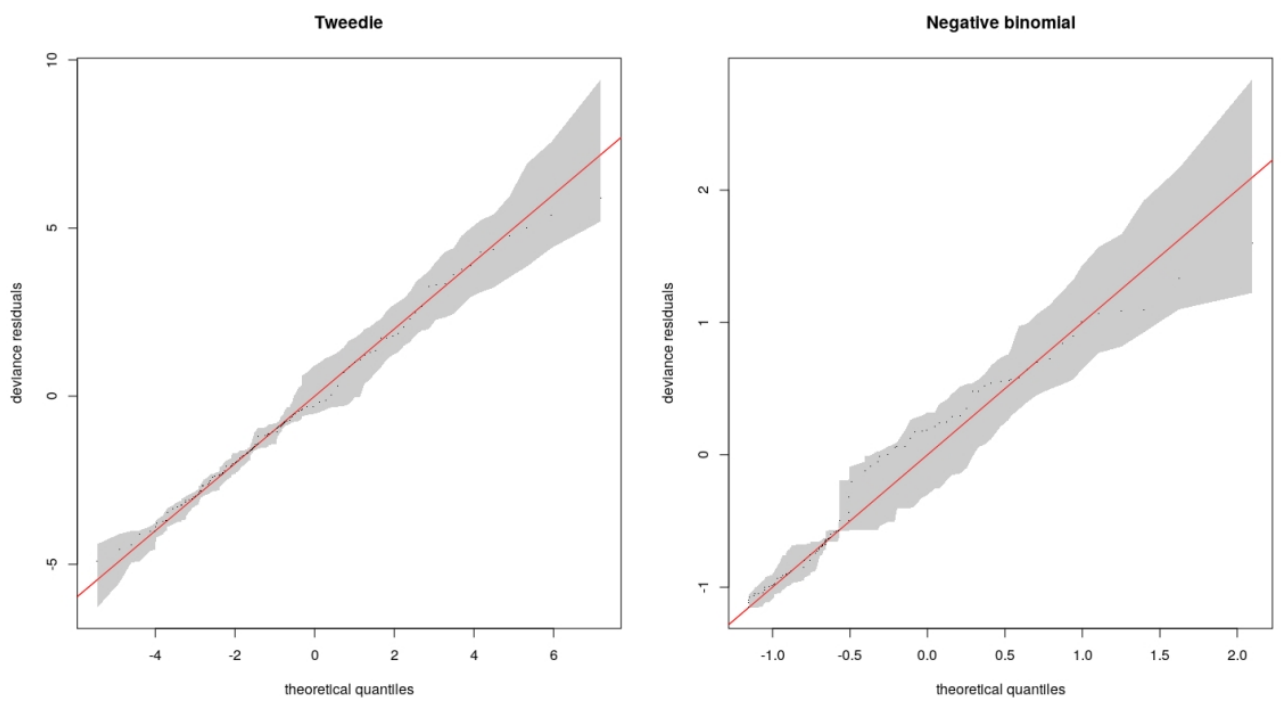

Figure 3

$381 \times 213 \mathrm{~mm}(96 \times 96$ DPI)

John Wiley \& Sons 

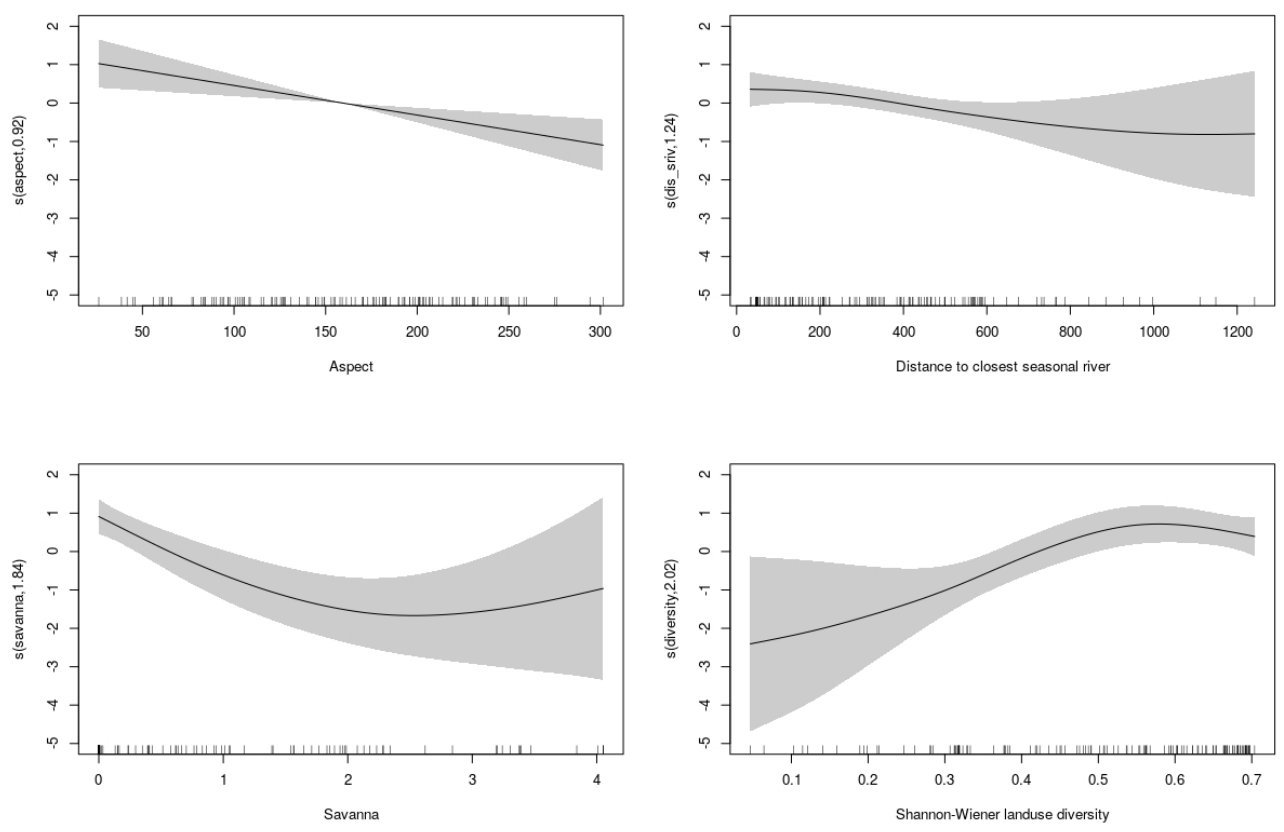

Figure 4

$425 \times 293 \mathrm{~mm}(72 \times 72 \mathrm{DPI})$

John Wiley \& Sons 


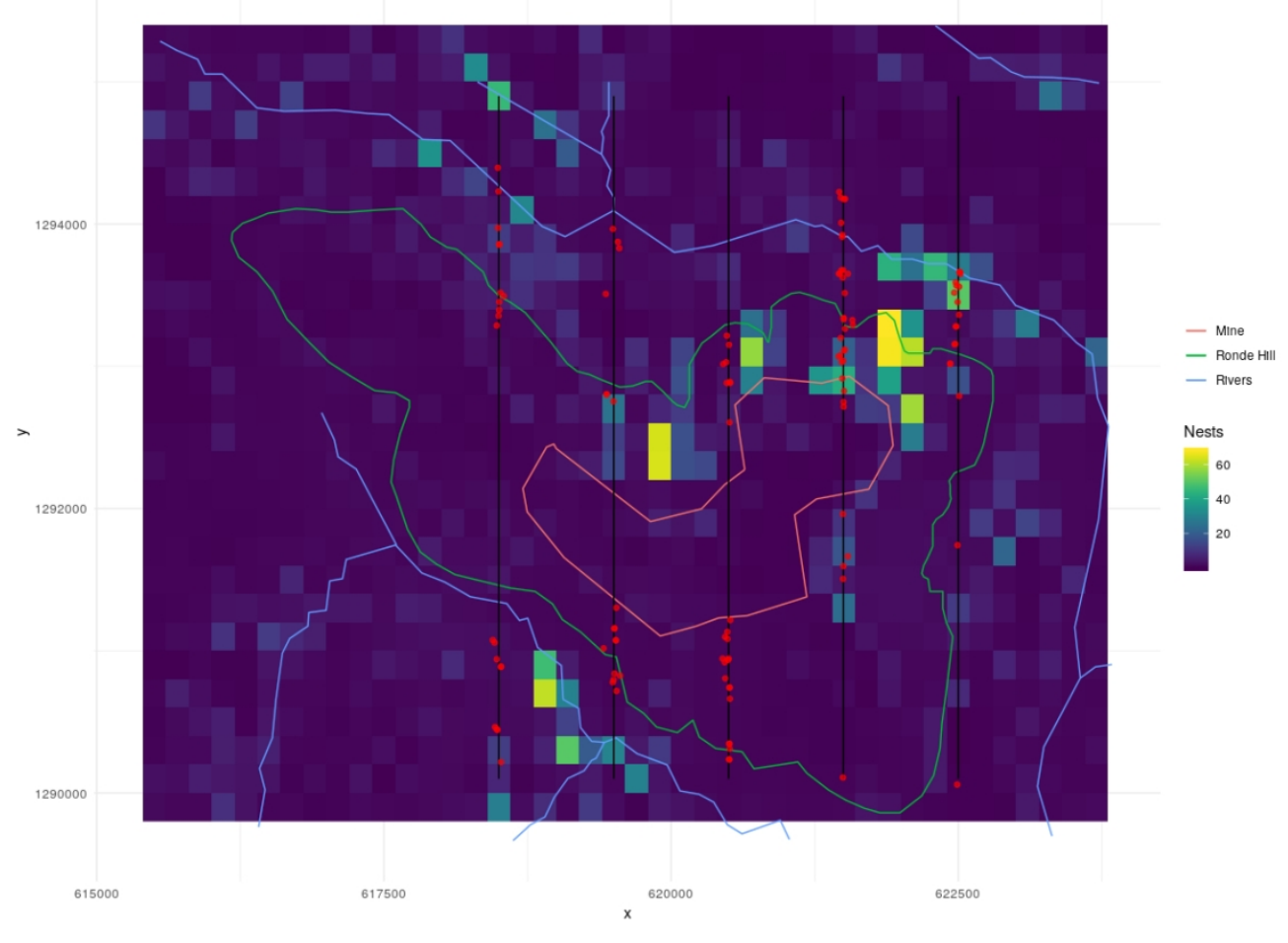

Figure 5

$423 \times 313 \mathrm{~mm}(72 \times 72 \mathrm{DPI})$

John Wiley \& Sons 


\section{Supplementary information from 'Density and distribution of western chimpanzees around a bauxite deposit in the Boé Sector, Guinea-Bissau' \\ José F. C. Wenceslau \\ Filipe S. Dias \\ Tiago A. Marques \\ David L. Miller}

\section{Introduction}

In this document we present the $\mathrm{R}$ code we used to generate the results we present and discuss in "Density and distribution of western chimpanzees around a bauxite deposit in the Boé Sector, Guinea-Bissau."

\section{Load required packages}

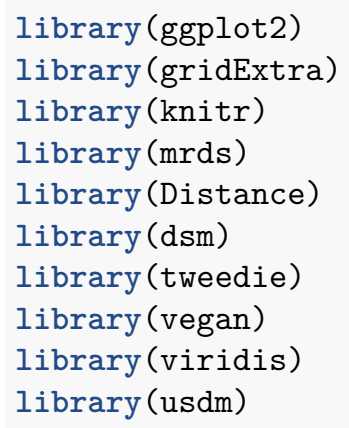


2. Exploratory data analysis

2.1 Histogram of observed distances

\section{Histogram of observed distances}

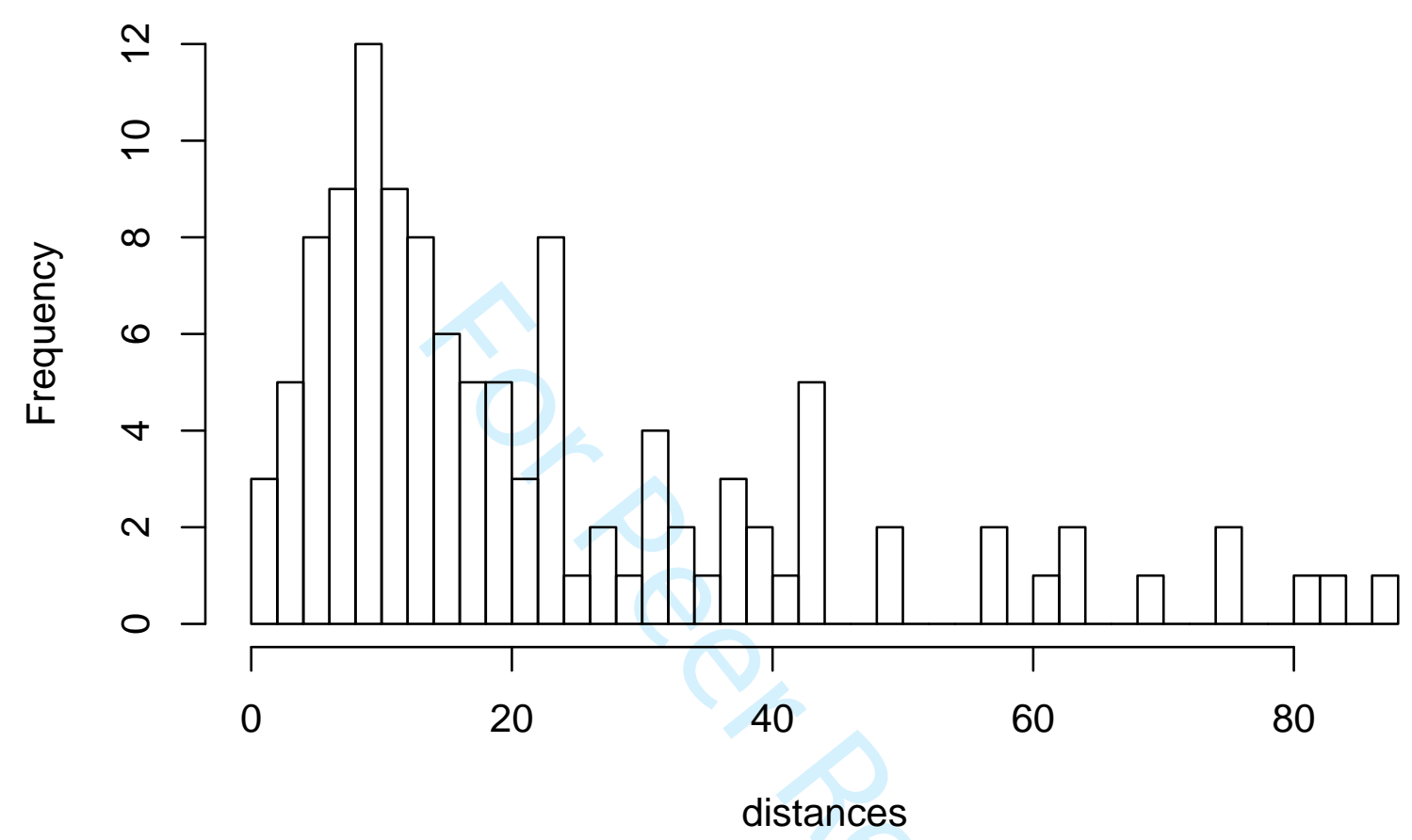


2.2 Do observed distances change as function of covariates?

Observed distances vs Decay

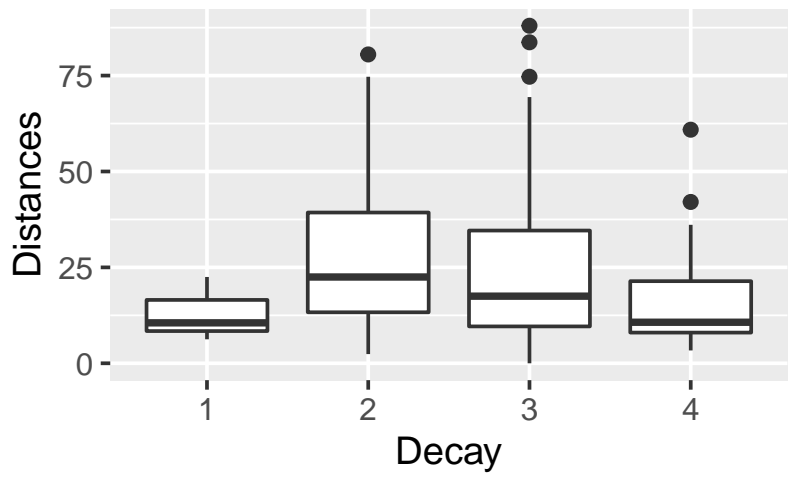

Observed distances vs Cluster size

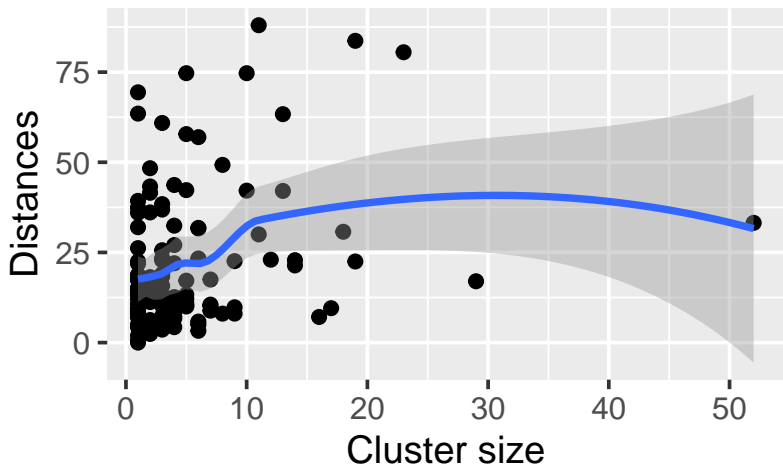

\section{Fit detection functions}

\subsection{Conventional distance sampling (CDS)}

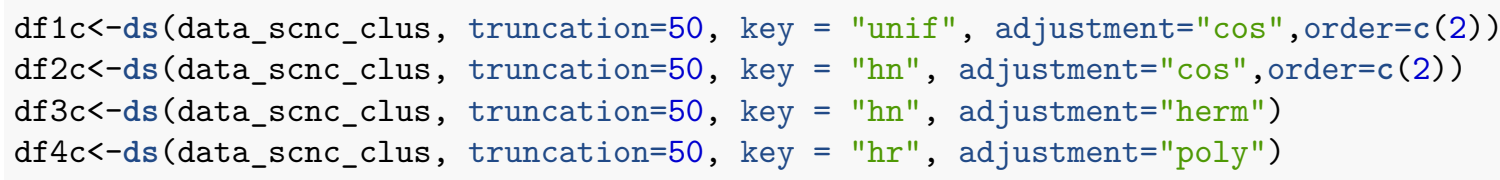

\subsection{Multiple-covariate distance sampling (MCDS)}

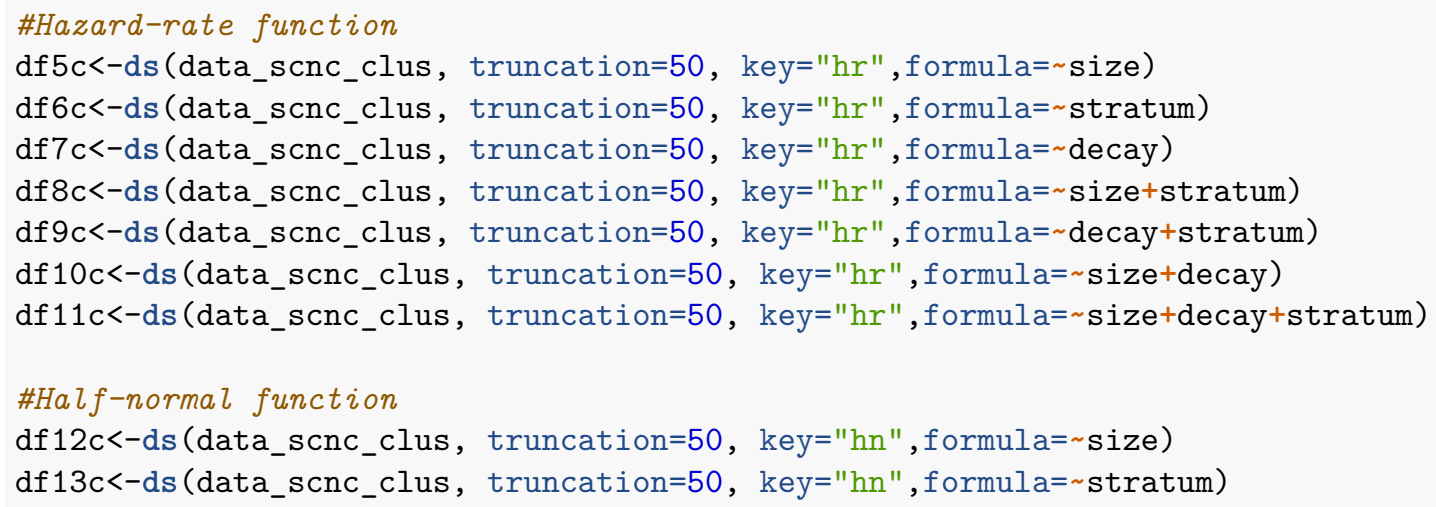


df $14 \mathrm{c}<-$ ds (data_scnc_clus, truncation $=50, k e y=" h n "$, formula $=\sim$ decay) df $15 c<-d s$ (data_scnc_clus, truncation $=50$, key $=" \mathrm{hn} "$, formula $=\sim$ size+stratum) df $16 \mathrm{c}<-$ ds (data_scnc_clus, truncation $=50, k e y=" h n "$, formula $=\sim$ decay+stratum) df $17 \mathrm{c}<-d s$ (data_scnc_clus, truncation $=50$, key $=" \mathrm{hn} "$, formula $=\sim$ size+decay) df $18 \mathrm{c}<-$ ds (data_scnc_clus, truncation=50, key="hn", formula $=\sim$ size+decay+stratum)

\subsection{Compare candidate detection functions based on AIC and goodness of fit test (Cramer von Mises)}

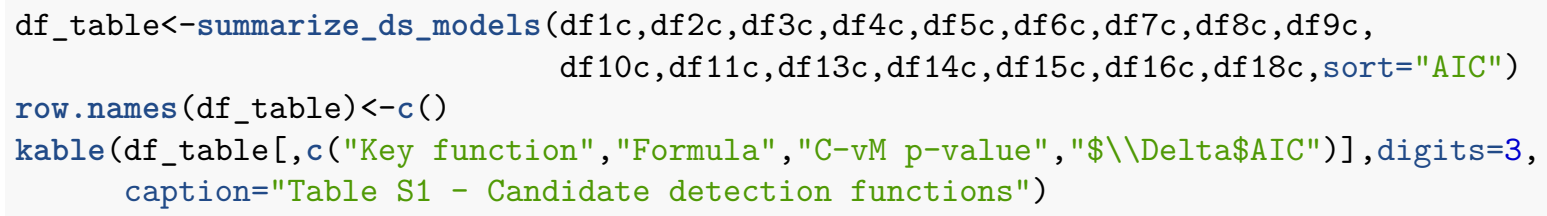

Table 1: Table S1 - Candidate detection functions

\begin{tabular}{llrr}
\hline Key function & Formula & C-vM p-value & $\Delta$ AIC \\
\hline Hazard-rate & $\sim$ size & 0.391 & 0.000 \\
Hazard-rate & $\sim$ size + decay & 0.414 & 0.360 \\
Hazard-rate & $\sim$ decay & 0.440 & 1.245 \\
Hazard-rate & $\sim 1$ & 0.445 & 1.319 \\
Half-normal & $\sim$ decay & 0.325 & 1.415 \\
Half-normal & $\sim 1$ & 0.346 & 2.344 \\
Uniform with cosine adjustment terms of order 1,2 & NA & 0.353 & 3.020 \\
Half-normal with cosine adjustment term of order 2 & $\sim 1$ & 0.305 & 3.477 \\
Hazard-rate & $\sim$ size + stratum & 0.404 & 3.764 \\
Hazard-rate & $\sim$ size + decay + stratum & 0.397 & 4.087 \\
Half-normal & $\sim$ size + decay + stratum & 0.306 & 4.448 \\
Hazard-rate & $\sim$ stratum & 0.465 & 5.093 \\
Hazard-rate & $\sim$ decay + stratum & 0.422 & 5.101 \\
Half-normal & $\sim$ decay + stratum & 0.311 & 5.357 \\
Half-normal & $\sim$ size + stratum & 0.316 & 5.510 \\
Half-normal & $\sim$ stratum & 0.368 & 6.241 \\
\hline
\end{tabular}

\subsection{Summary and plot of the selected detection function}

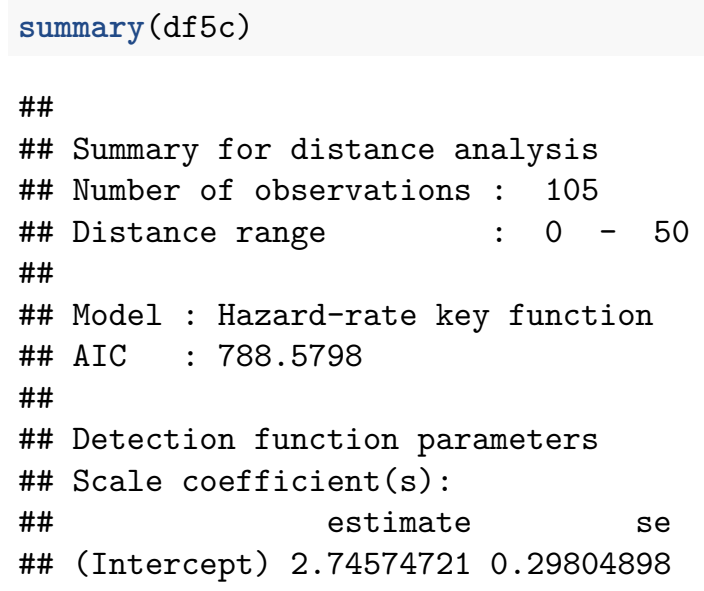



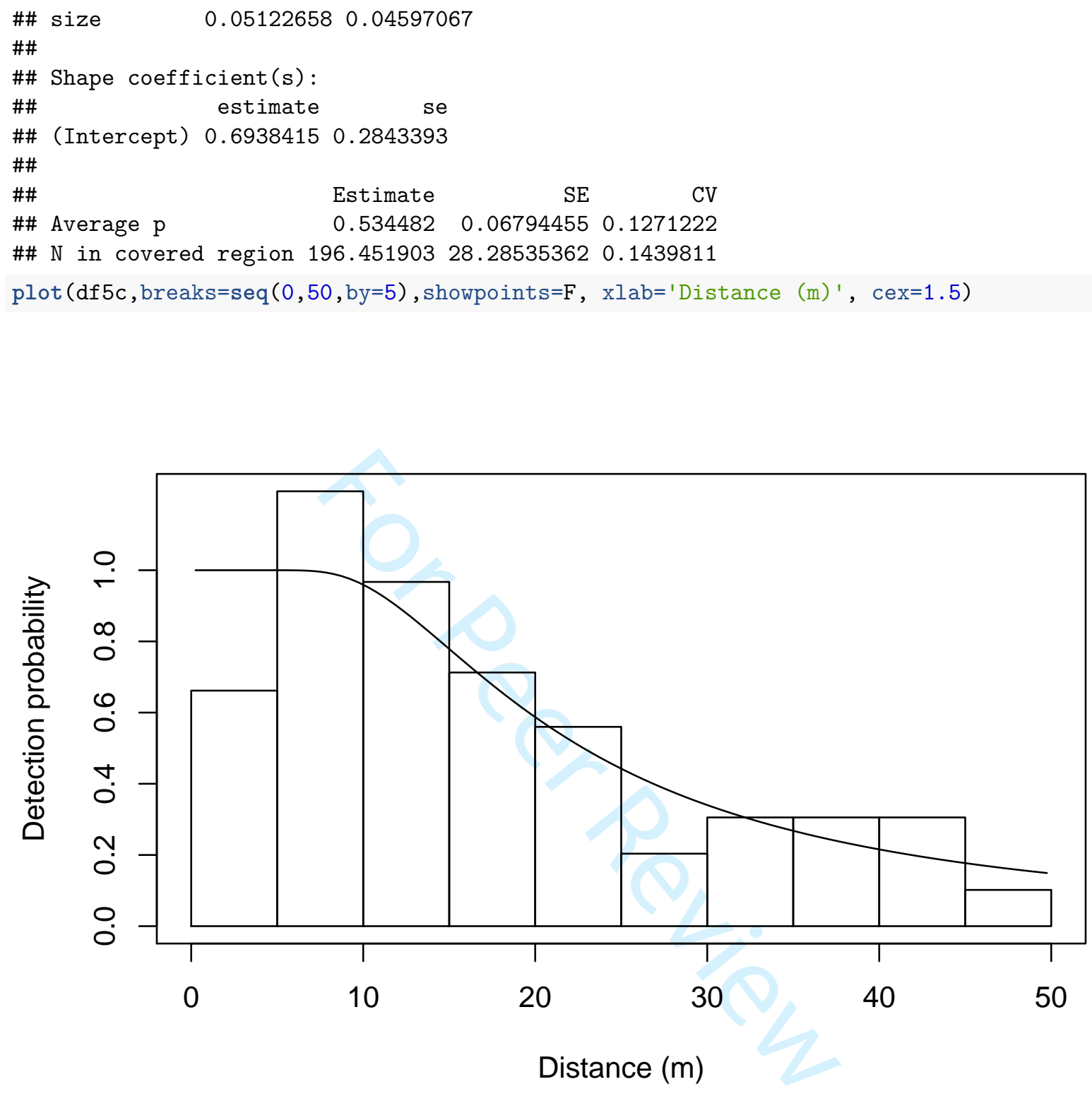

\section{Density surface models}

\subsection{Covariates}

1. altitude - mean altitude $(\mathrm{m})$

2. slope - mean slope (\%)

3. zone_type - conservation (cz) or non-conservation zone (ncz)

4. aspect - mean aspect (radians)

5. dis_priv - distance to closest permanent river (m)

6. dis_sriv - distance to closest seasonal river (m)

7. dis_road - distance to closest road (m)

8. dis_city - distance to closest city (m)

9. agriculture - area of agriculture (ha)

10. urban - area of urban areas (ha) 
11. prim_forest - area of primary forest (ha)

12. savanna - area of savanna (ha)

13. sec_forest - area of secondary forest (ha)

14. diversity - Shannon-Wiener diversity of landuses

\subsection{Calculate Shannon-Wiener landuse diversity}

library (vegan)

segment_data\$diversity<-diversity (segment_data [, $11: 15]$ ) 


\subsection{Explore covariates}

5.3.1 Histograms with the covariates
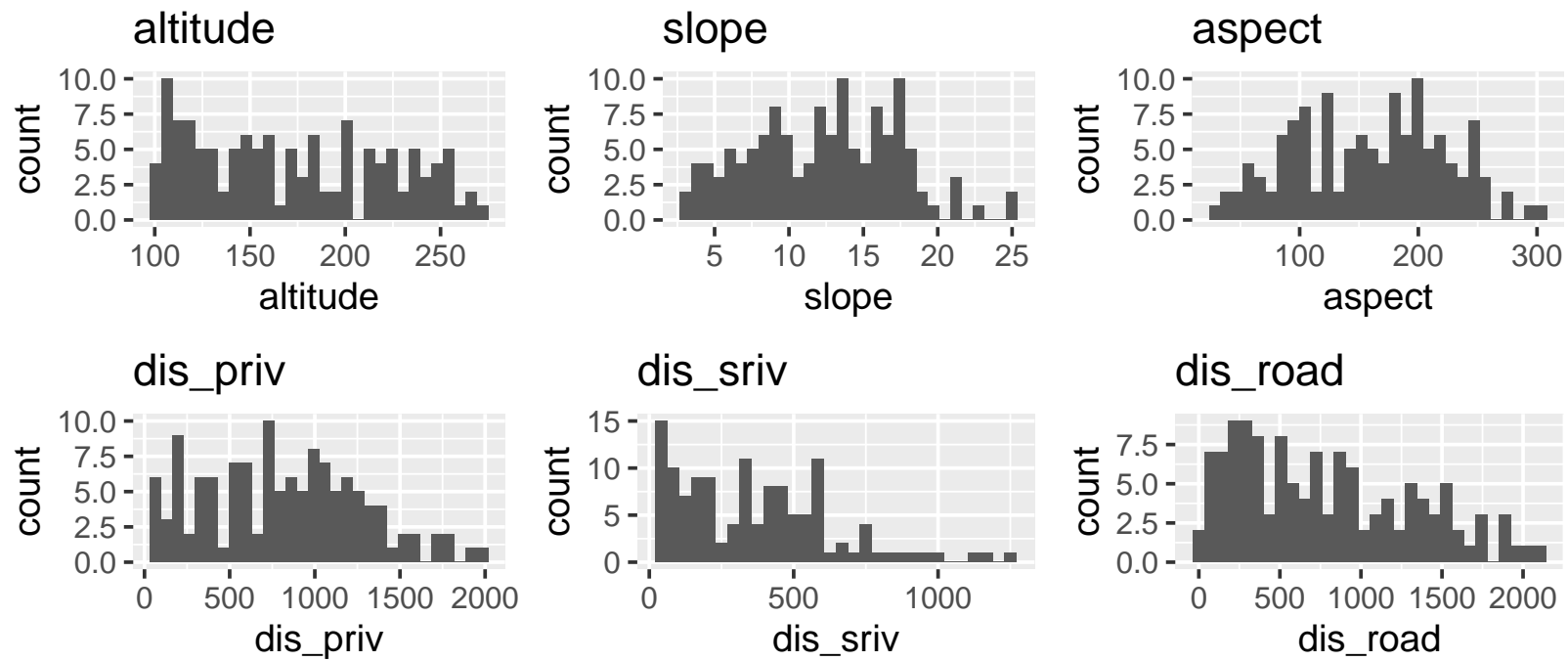

dis_road

dis_city

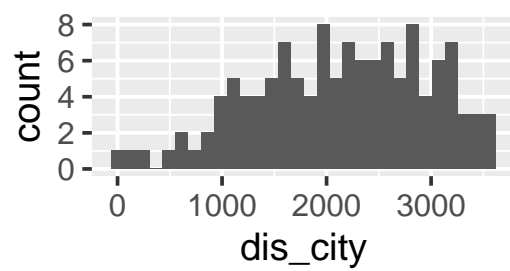

agriculture
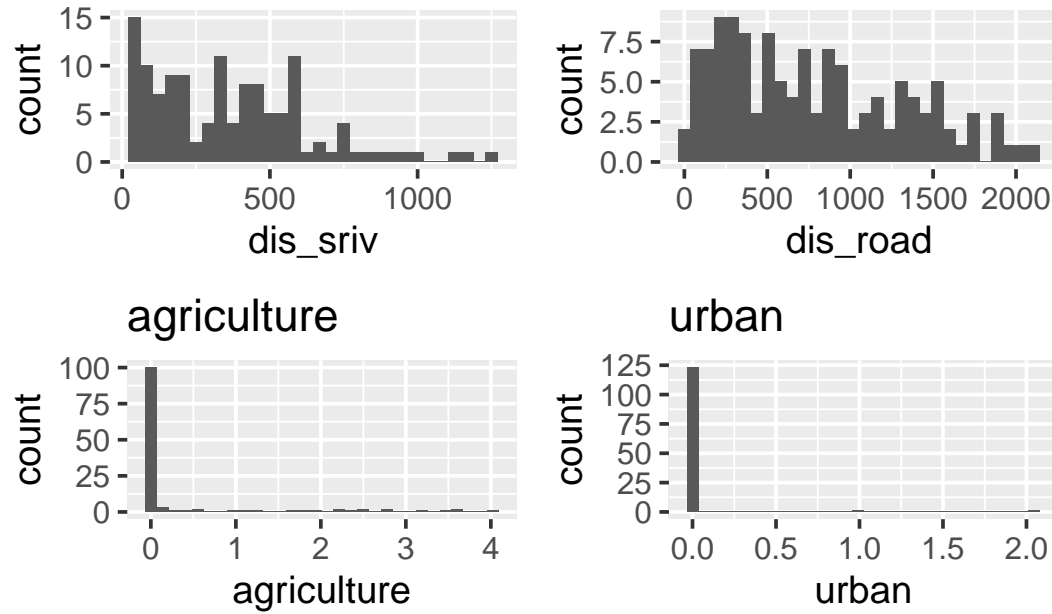

prim_forest

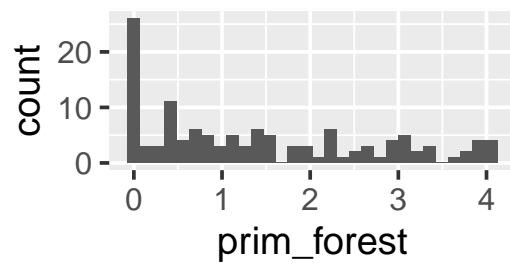

diversity

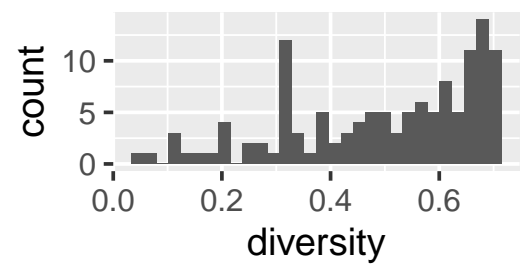

savanna

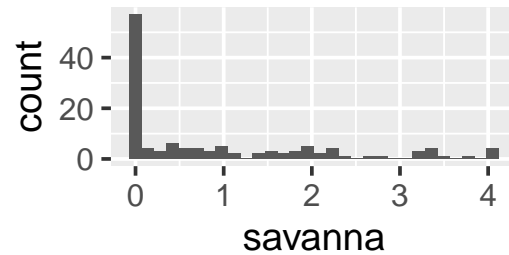

urban

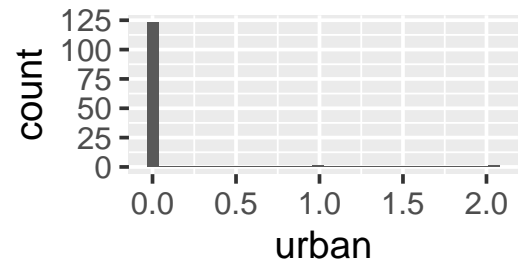

sec_forest

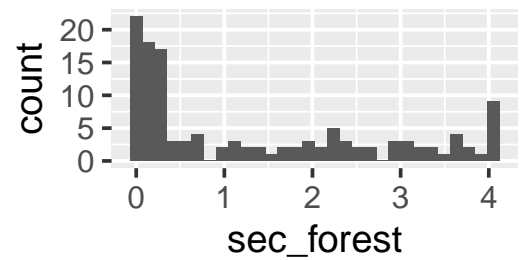

\subsubsection{Assess correlations between variables}

vifstep (subset (segment_data, $\operatorname{select=c}(6: 17,22)), t h=3$ )

\#\# 2 variables from the 13 input variables have collinearity problem:

\#\#

\#\# sec_forest dis_road 
\#\#

\#\# After excluding the collinear variables, the linear correlation coefficients ranges between:

\#\# min correlation ( urban aspect ): -0.006550346

\#\# max correlation (dis_priv altitude ): 0.6224637

\#\#

\#\# --------- VIFs of the remained variables --------

\#\# Variables VIF

\#\# 1 altitude 2.679982

\#\# 2 slope 1.744131

\#\# 3 aspect 1.295983

\#\# 4 dis_priv 2.884064

\#\# 5 dis_sriv 1.666188

\#\# 6 dis_city 1.930337

\#\# 7 agriculture 1.674478

\#\# urban 1.438926

\#\# 9 prim_forest 1.440064

\#\# 10 savanna 2.263407

\#\# 11 diversity 2.368425

\subsection{Tweedie model}

\subsubsection{Fit the final model}

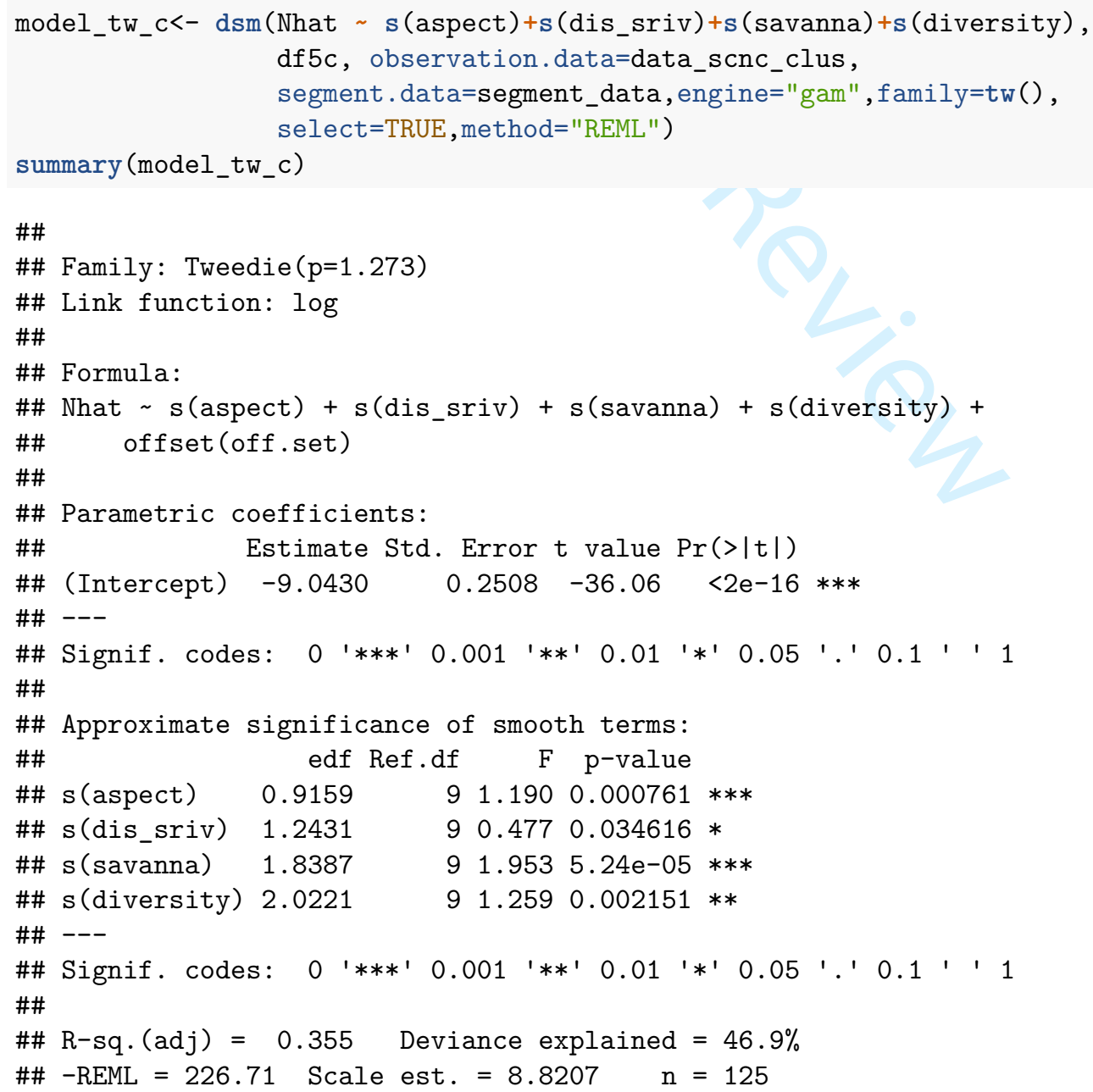




\subsubsection{Model validation}
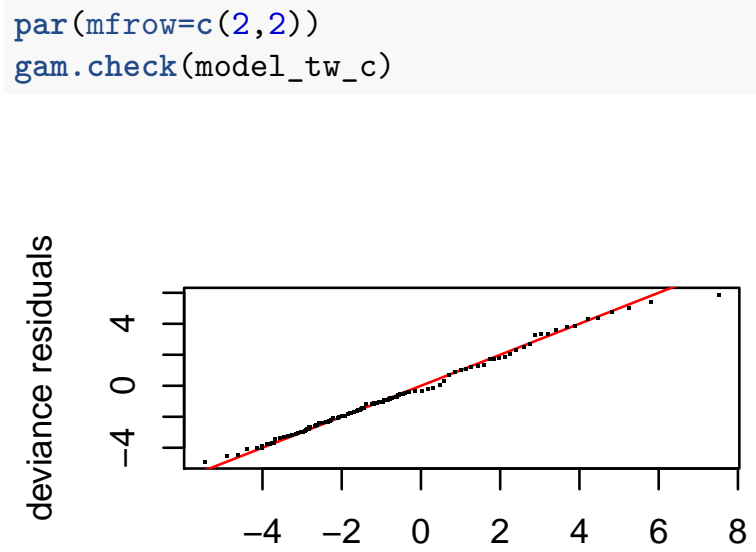

Resids vs. linear pred.

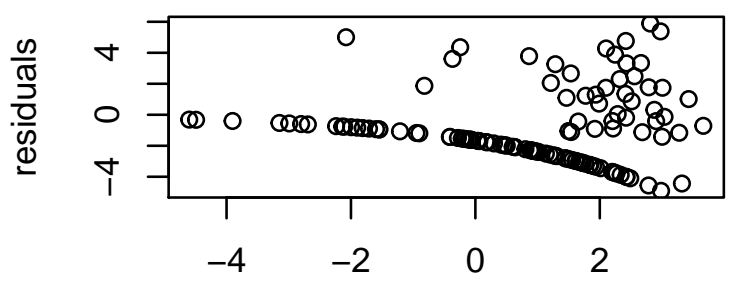

linear predictor

\section{Histogram of residuals}

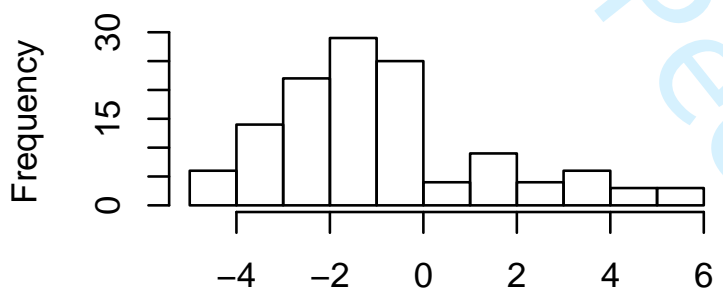

Residuals
Response vs. Fitted Values

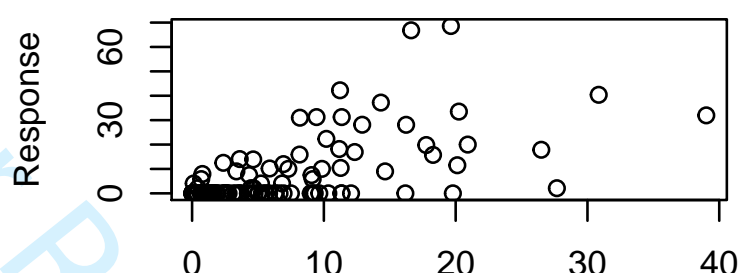

Fitted Values

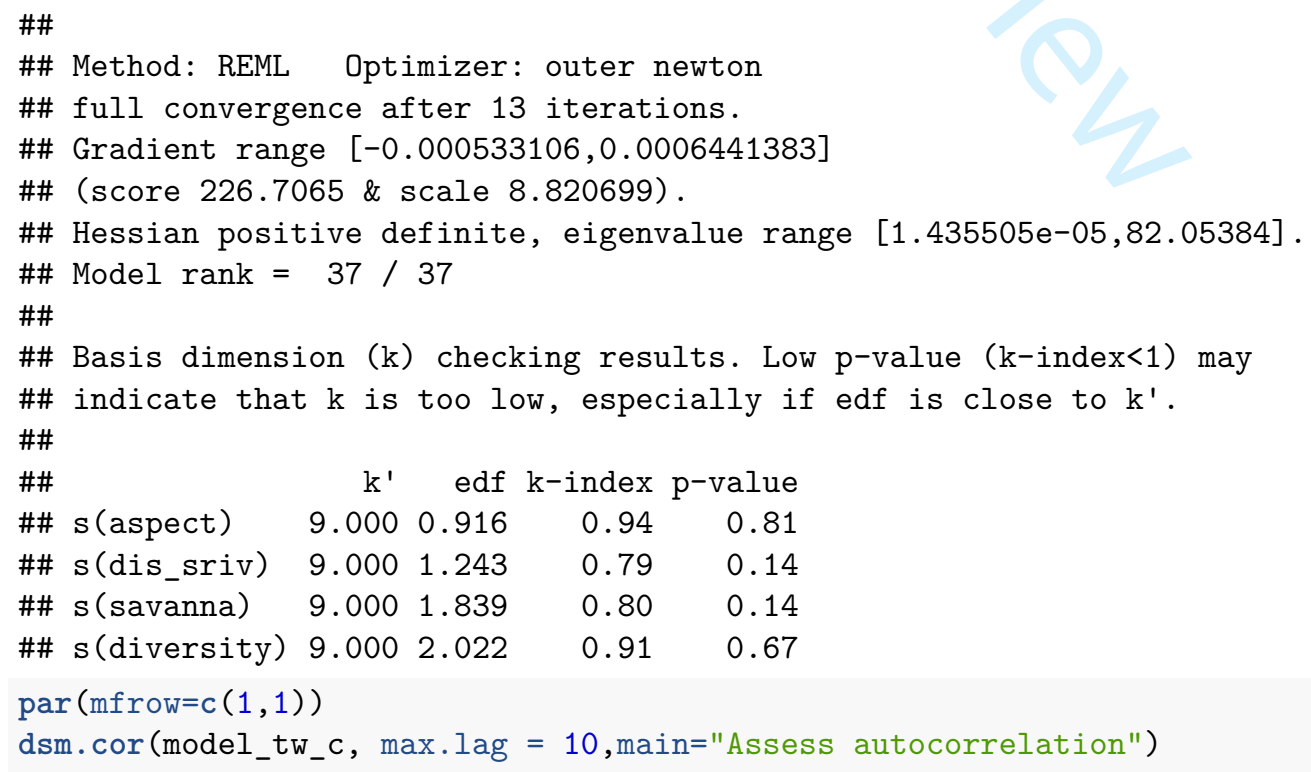


Assess autocorrelation

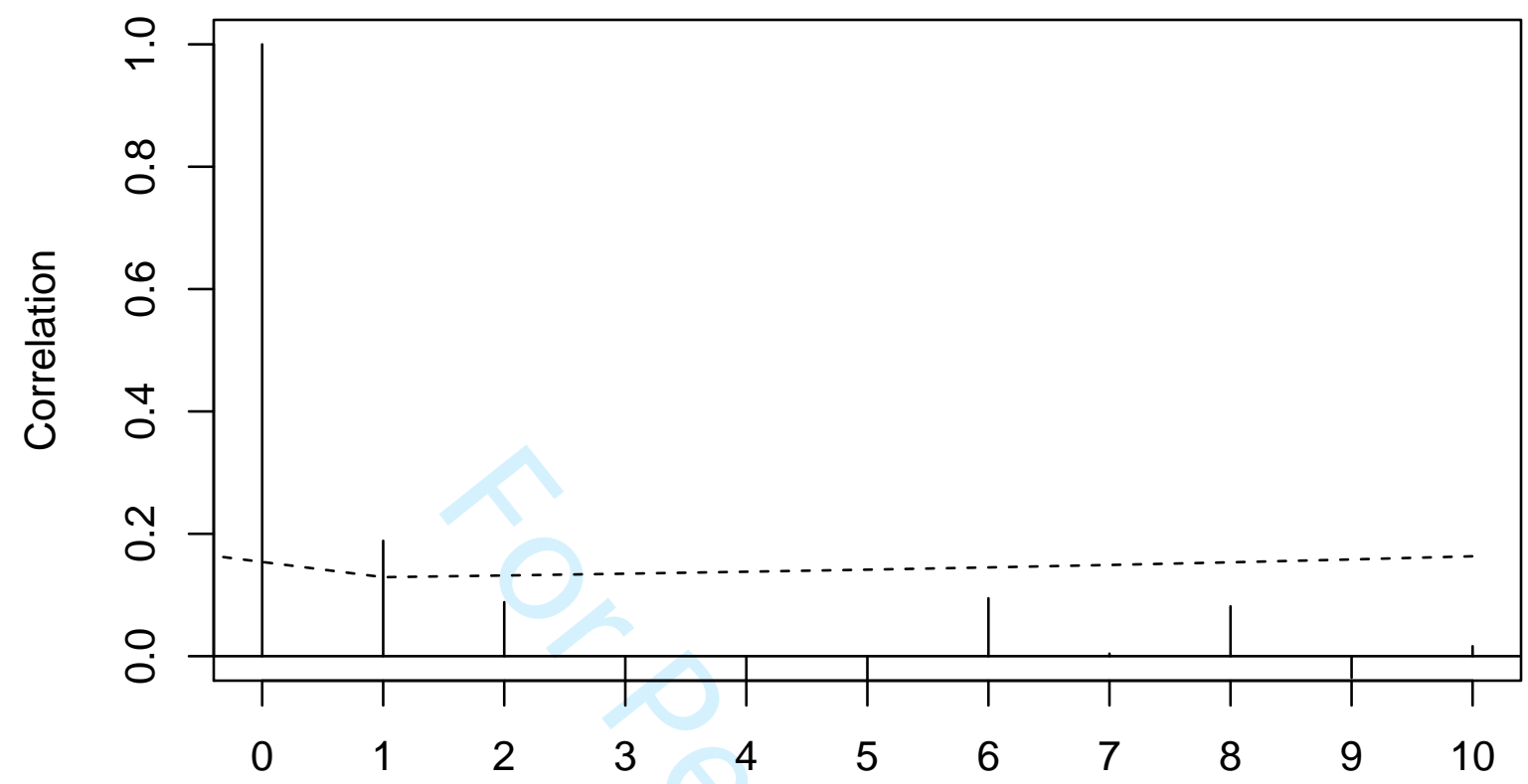

Lag

concurvity (model_tw_c)

\#\# para s(aspect) s(dis_sriv) s(savanna) s(diversity)

$\begin{array}{llllll}\text { \#\# worst } & 1.777762 \mathrm{e}-24 & 0.6080265 & 0.5696487 & 0.6269396 & 0.6599517\end{array}$

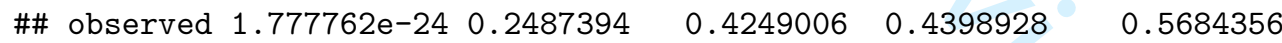

$\begin{array}{llllll}\text { \#\# estimate } 1.777762 \mathrm{e}-24 & 0.2387085 & 0.4267187 & 0.4632259 & 0.5252859\end{array}$

\subsubsection{Plot smoothers}

$\operatorname{par}(\operatorname{mfrow}=c(2,2))$

plot (model_tw_c, shade=TRUE, $y \lim =c(-5,2)$, fig.height $=7$, select $=1, x l a b="$ Aspect")

plot (model_tw_c, shade=TRUE, $y \lim =c(-5,2), \mathrm{fig} \cdot \mathrm{height}=7$, select $=2, \mathrm{xlab}=$ "Distance to closest seasonal rive plot (model_tw_c, shade=TRUE, ylim=c $(-5,2)$, fig.height=7, select=3, xlab="Savanna")

plot (model_tw_c, shade=TRUE, $y \lim =c(-5,2)$, fig.height=7, select=4,xlab="Shannon-Wiener landuse diversity" 

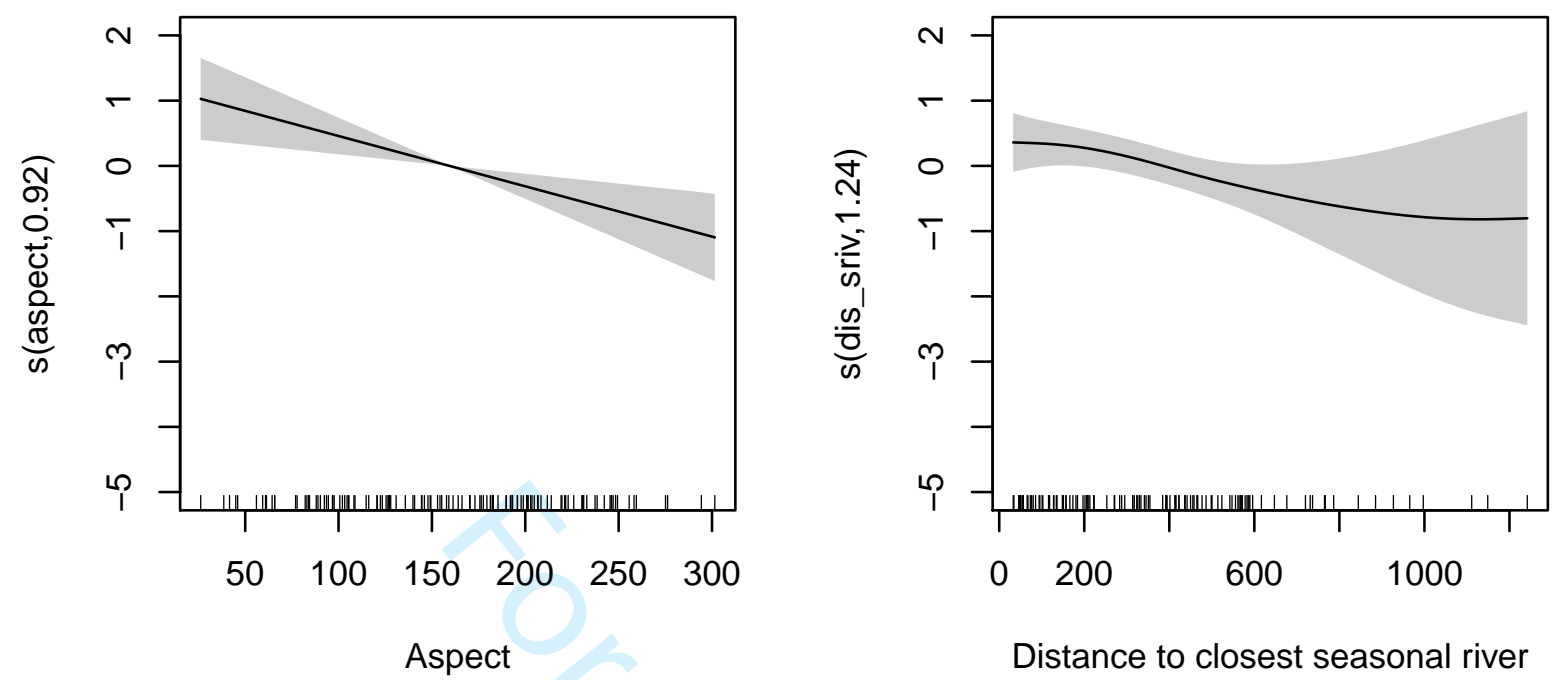

Distance to closest seasonal river
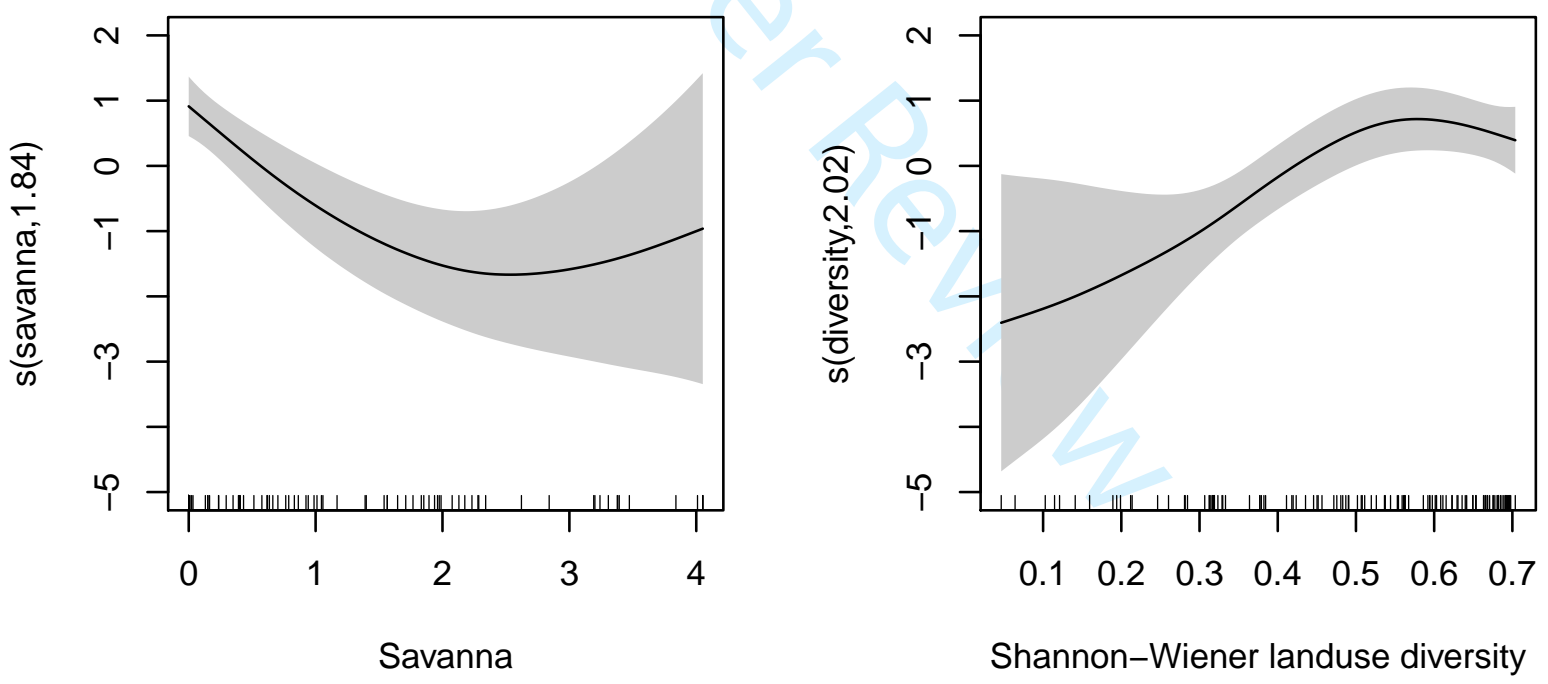

$\operatorname{par}(\operatorname{mfrow}=c(1,1))$

5.5 Negative binomial model

\subsubsection{Fit the final model}

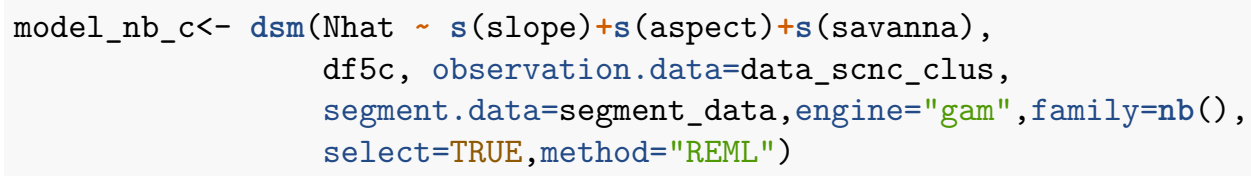


\#\# Warning in make.data(response, ddf.obj, segment.data, observation.data, : \#\# Some observations are outside of detection function truncation!

\subsubsection{Model validation}

$\operatorname{par}(\operatorname{mfrow}=\mathrm{c}(2,2))$

gam.check (model_nb_c) 
Resids vs. linear pred.

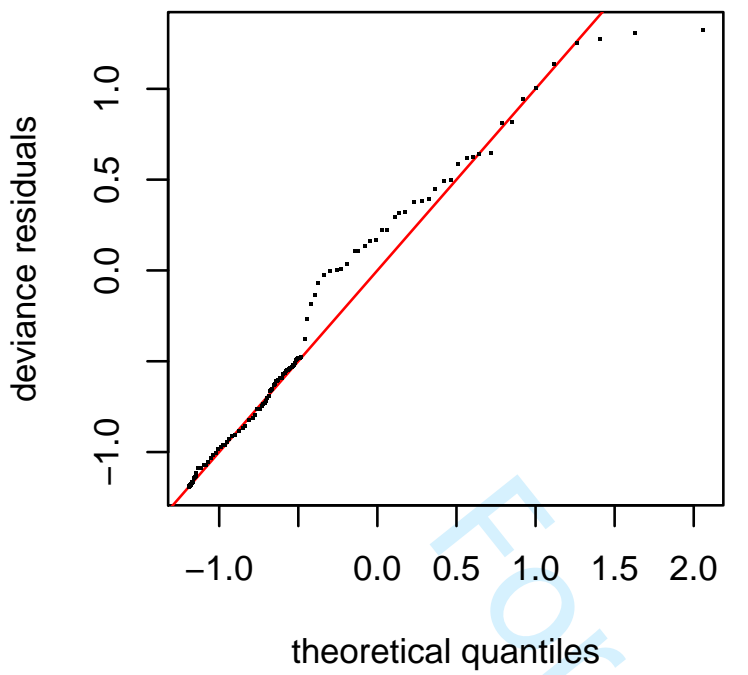

Histogram of residuals

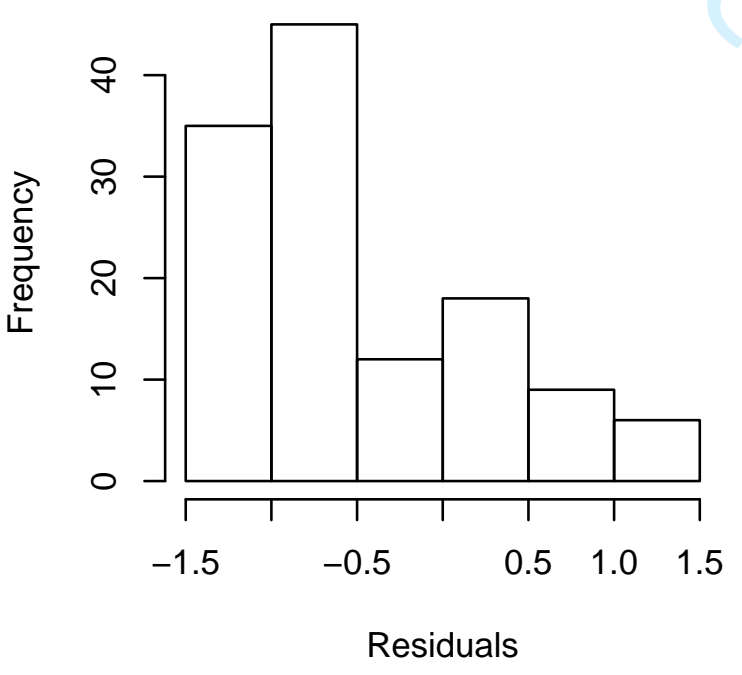

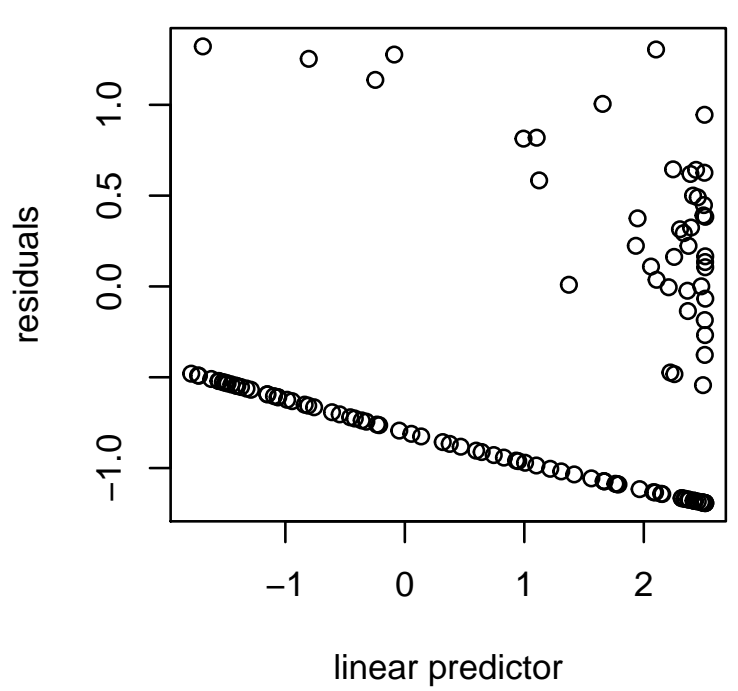

Response vs. Fitted Values

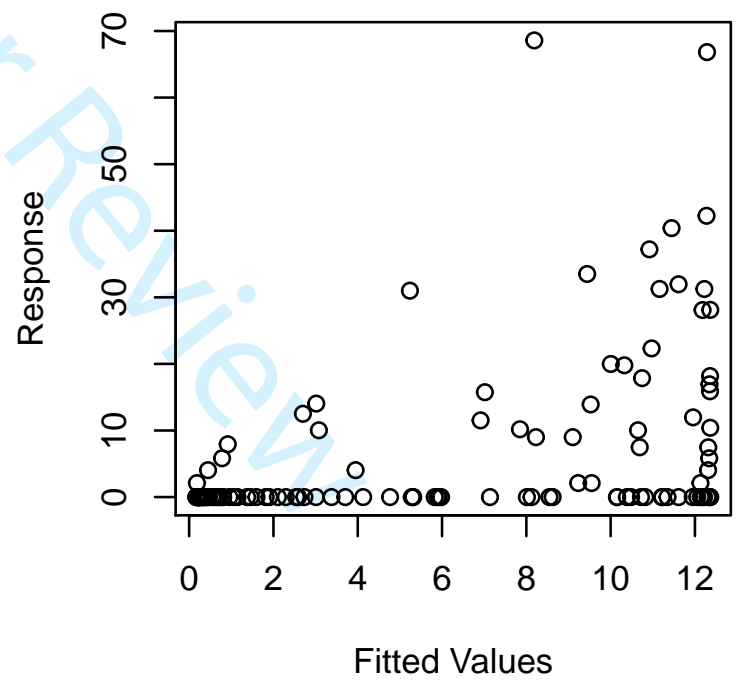

\#\#

\#\# Method: REML Optimizer: outer newton

\#\# full convergence after 11 iterations.

\#\# Gradient range [-8.869582e-05,9.496902e-05]

\#\# (score 252.3186 \& scale 1).

\#\# Hessian positive definite, eigenvalue range [6.644452e-06,24.35469] .

\#\# Model rank $=28 / 28$

\#\#

\#\# Basis dimension $(\mathrm{k})$ checking results. Low p-value $(\mathrm{k}-\mathrm{index}<1)$ may

\#\# indicate that $\mathrm{k}$ is too low, especially if edf is close to k'.

\#\# 


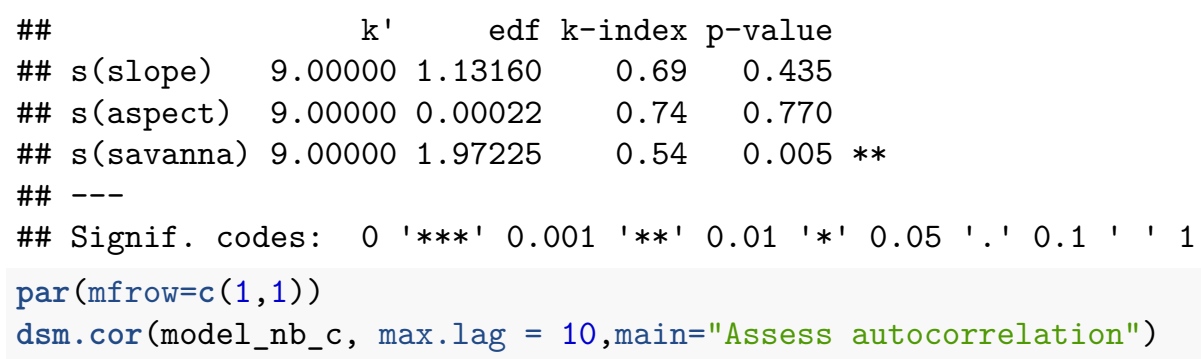

\section{Assess autocorrelation}

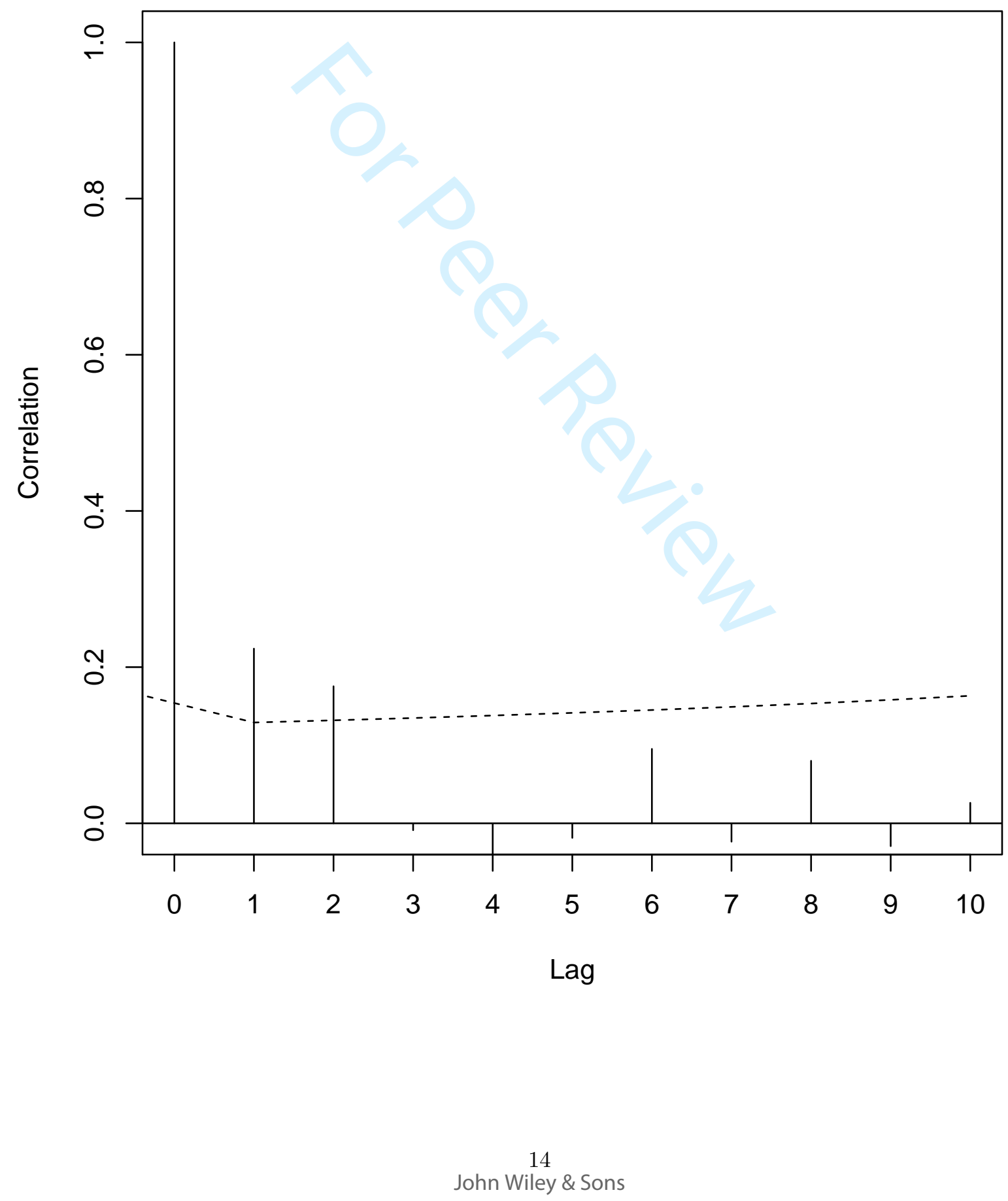




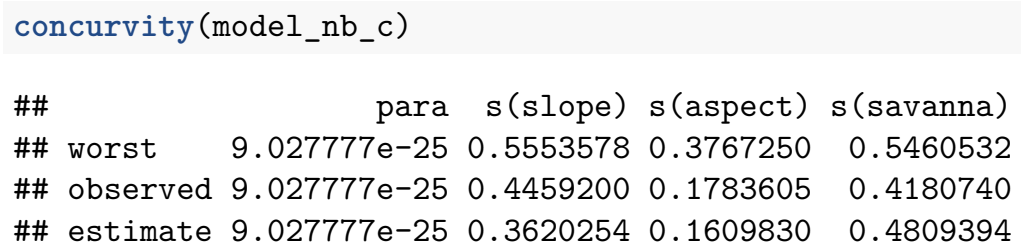

\subsubsection{Plot smoothers}

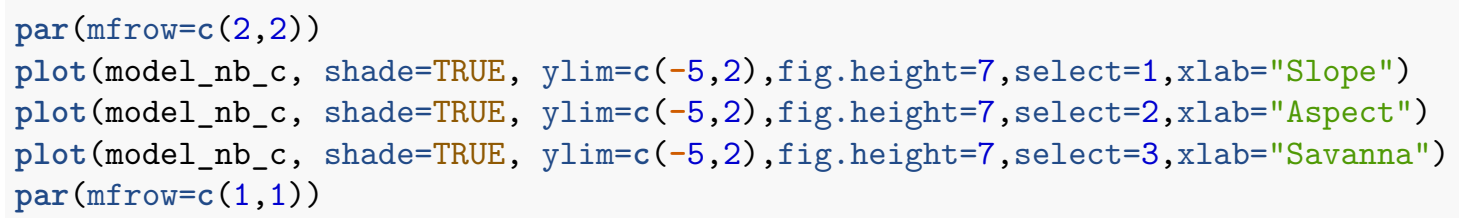



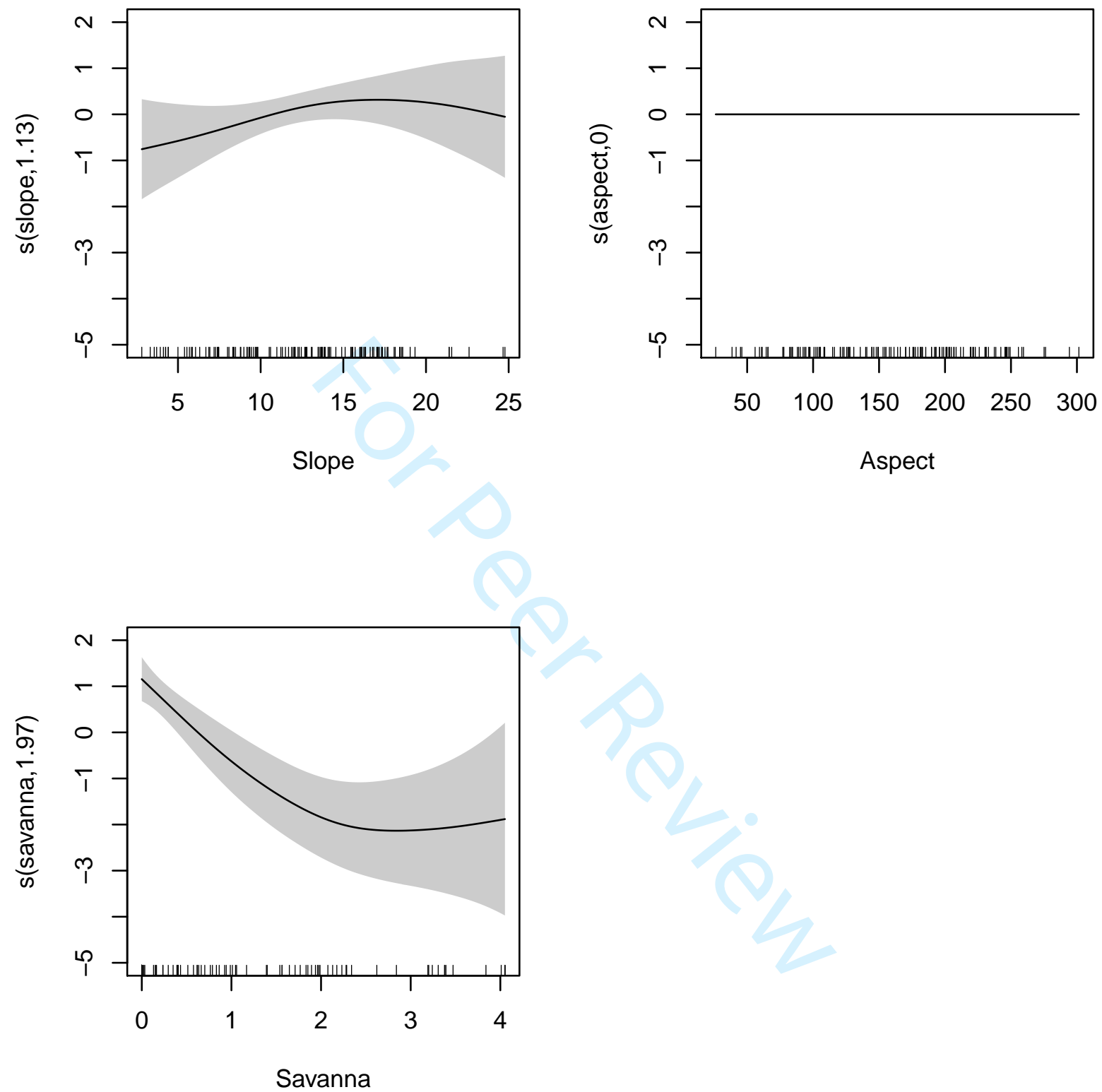

5.6 Which model should we select?

$\operatorname{par}(\operatorname{mfrow}=\mathrm{c}(1,2))$

qq. gam (model_tw_c, rep=100, main="Tweedie")

qq.gam (model_nb_c,rep=100, main="Negative binomial") 
Tweedie

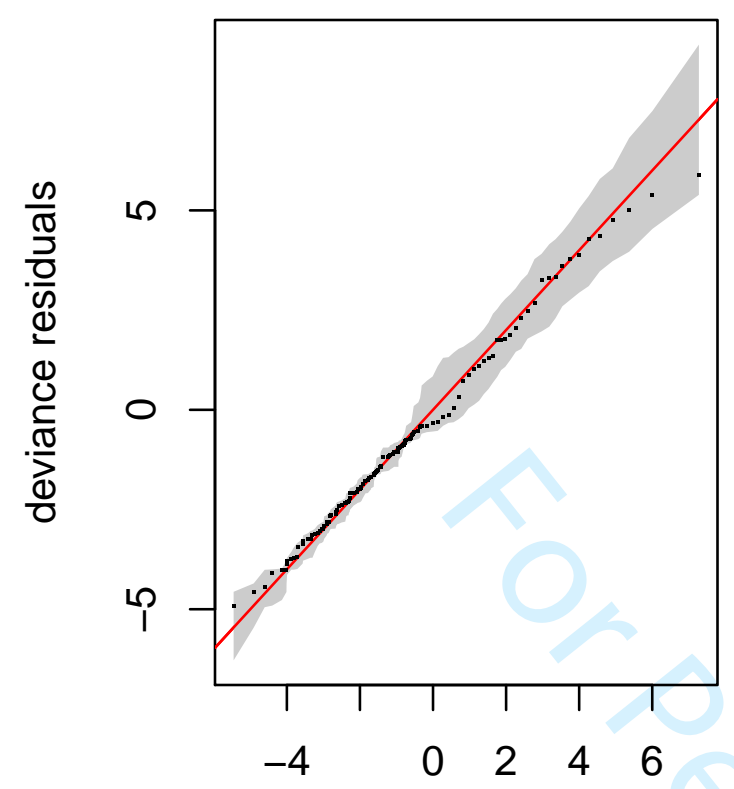

theoretical quantiles
Negative binomial

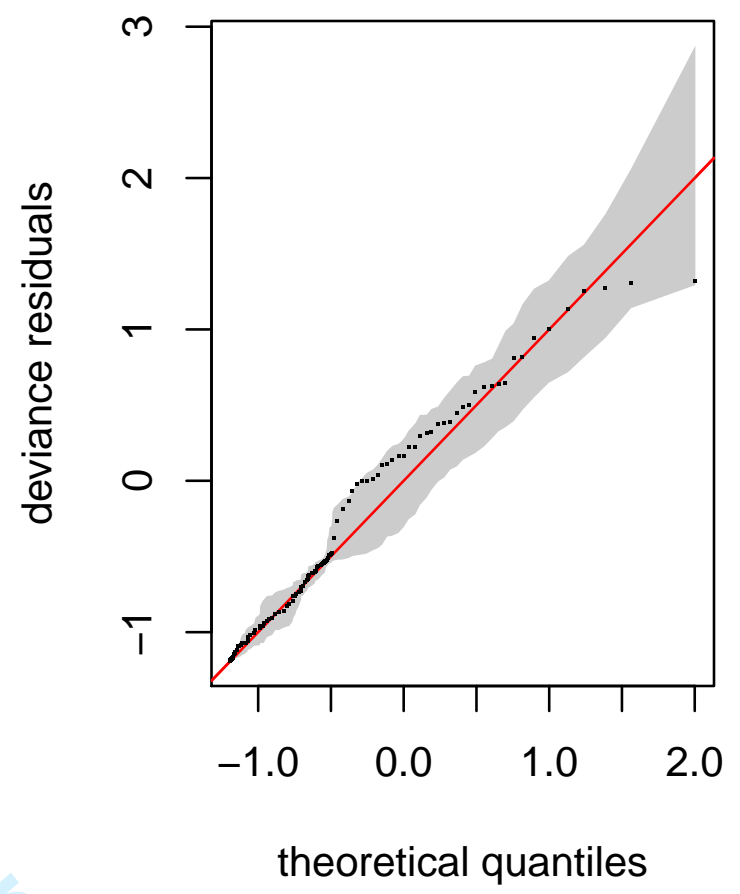

$\operatorname{par}(\operatorname{mfrow}=c(1,1))$

This plot shows a comparison of models with Tweedie (left) and negative binomial (right) response distributions by quantile-quantile plots. Good fit is indicated by agreement between observed and fitted (residual) quantiles (i.e., points being close to the red line). $90 \%$ reference bands are shown in grey allowing judgement of the deviation from the line. The negative binomial points fall further away from the red line than those for the Tweedie, indicating model misspecification.

\section{Model predictions}

\subsection{Calculate offset}

off.set <- (200*200) \#grid is 200 m x $200 \mathrm{~m}$

\subsection{Predictions from the Tweedie model}

\subsubsection{Calculate predicted abundances}

model_tw.pred_c $<-$ predict (model_tw_c, preddata, off.set)

preddata\$TW_ab_c<-unname (model_tw.pred_c)

6.2.2 Plot predicted abundances alongside transects and clusters of nests

$\mathrm{p}<-\operatorname{ggplot}$ (preddata, aes (x, y))+theme_minimal ()

$\mathrm{p}<-\mathrm{p}+$ geom_raster $\left(\operatorname{aes}\left(\mathrm{fill}=\mathrm{TW}_{-}\right.\right.$ab_c $\left.)\right)$ 

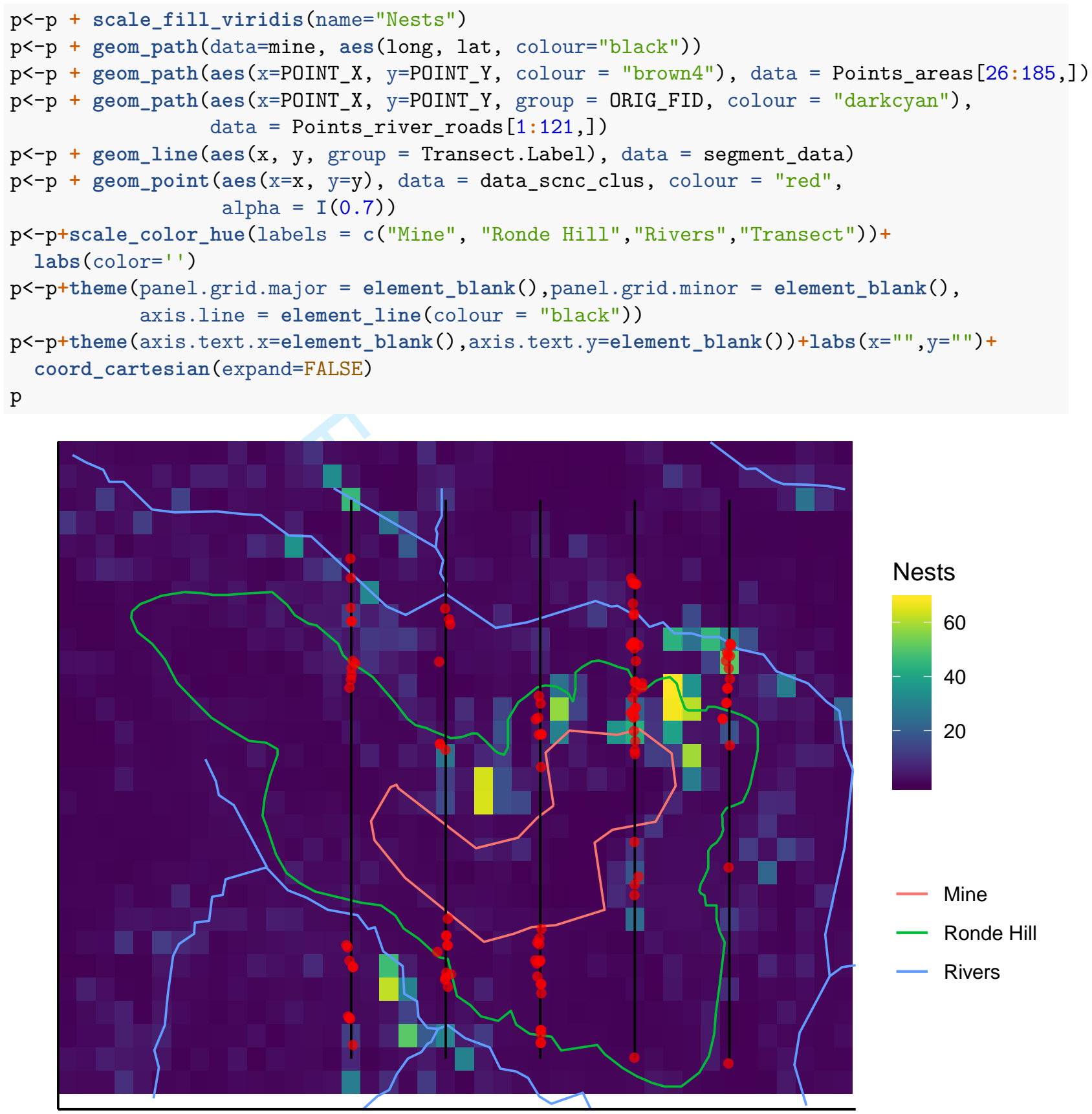

Nests

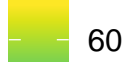

- Mine

- Ronde Hill

- Rivers

\subsubsection{Calculate prediction variances}

model_tw_var_c<-dsm.var.gam (model_tw_c, pred.data $=$ preddata, off. set $=$ off. set) summary (model_tw_var_c)

\#\# Summary of uncertainty in a density surface model calculated \#\# analytically for GAM, with delta method \#\# \#\# Approximate asymptotic confidence interval: \#\# $\quad 2.5 \% \quad$ Mean $97.5 \%$ 


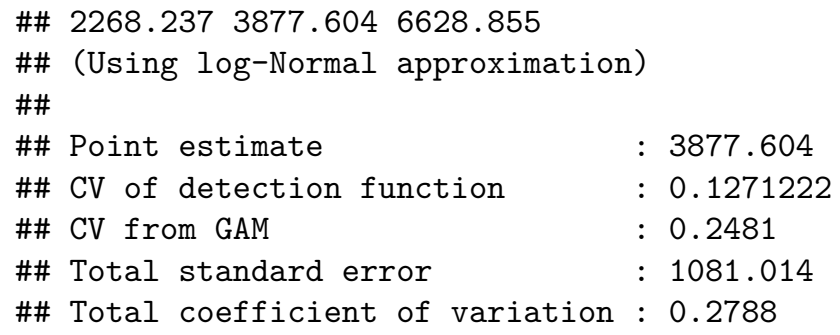

\section{Calculate density and abundance of nest building chimpanzees with the Tweedie model}

To calculate the density of chimpanzees we use the following formula:

D_weaned_chimpanzee $=\mathrm{D} \_$nests $/\left(\mathrm{r}^{*} \mathrm{t}\right)$

where "r" is the estimated rate of nest production per individual per day estimated to be 1.09 nests/individual/day by Plumptre \& Reynolds (1997) and "t" is the mean life of a nest estimated to be 194 days by Fleury-Brugiere \& Brugiere (2010).

Following this formula, the estimated number of weaned chimpanzees in the study area is:

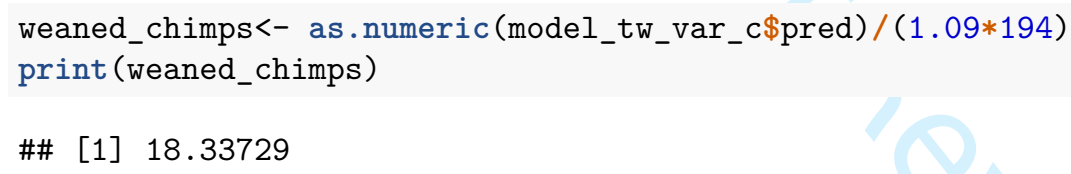

Now, we calculate the $95 \%$ confidence intervals for the number of weaned chimpanzees in the study area using the upper and lower bounds of the estimated number of nests (see above):

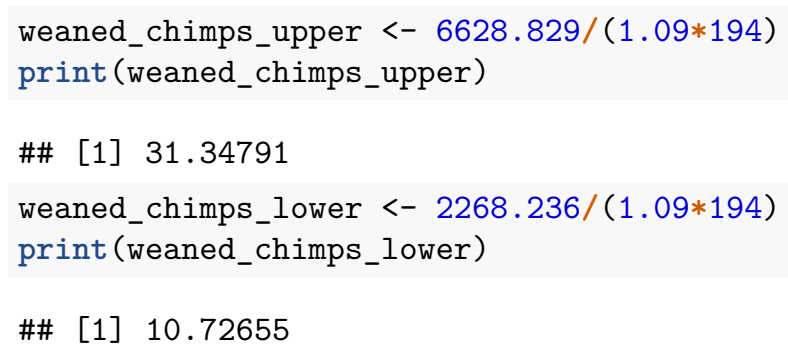

Considering the study area covers 47.04 squared kilometers, the number of chimpanzees per squared kilometer and the corresponding $95 \%$ confidence interval is:

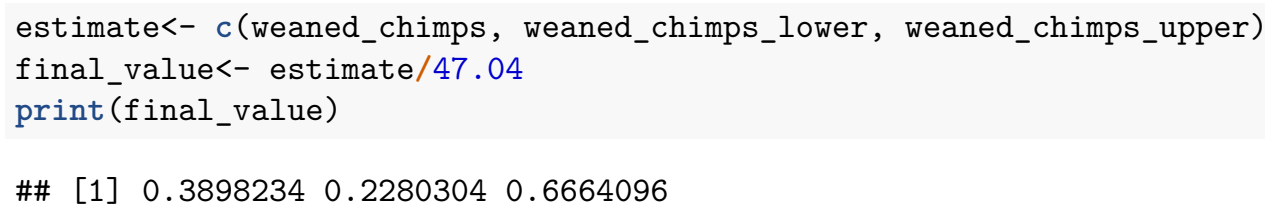

